\title{
A Zonally Averaged, Coupled Ocean-Atmosphere Model for Paleoclimate Studies
}

\author{
Thomas F. Stocker, ${ }^{*, \dagger}$ Daniel G. Wright, ${ }^{* *}$ and Lawrence A. MysaK* \\ *Centre for Climate and Global Change Research, Department of Atmospheric and Oceanic Sciences, \\ McGill University, Montréal, Québec, Canada \\ ** Department of Fisheries and Oceans, Bedford Institute of Oceanography, Dartmouth, Nova Scotia, Canada
}

(Manuscript received 31 May 1991, in final form 28 October 1991)

\begin{abstract}
A zonally averaged ocean model for the thermohaline circulation is coupled to a zonally averaged, one-layer energy balance model of the atmosphere to form a climate model for paleoclimate studies. The emphasis of the coupled model is on the ocean's thermohaline circulation in the Pacific, Atlantic, and Indian oceans. Each basin is individually resolved, and they are connected by the Southern Ocean through which mass, heat, and salt are exchanged. Under present-day conditions, the global conveyor belt is simulated: deep water is formed in the North Atlantic and the Southern Ocean, whereas both Pacific and Indian oceans show broad upwelling. Latitude-depth structures of modeled temperature and salinity fields, as well as depth-integrated meridional transports of heat and freshwater, compare well with estimates from observations when wind stress is included Ekman cells are present in the upper ocean and contribute substantially to the meridional fluxes at low latitudes, bringing them to close agreement with observed estimates.

The atmospheric component of the coupled climate model consists of a classical, time-dependent energy balance model; the seasonal cycle is not included. Observations and the ocean-to-atmosphere fluxes at steady state are used to determine the net downward shortwave radiation, constant greybody emissivity, eddy diffusivity parameterizing the meridional energy fluxes in the atmosphere, and evaporation and precipitation over the individual ocean basins.

When the two components are coupled after being spun up individually, the system remains steady provided that no intermittent convection is present in the ocean model. If intermittent convection is operating, the coupled model shows systematic deviations of the surface salinity, which may result in reversals of the thermohaline circulation. This climate drift can be inhibited by removing intermittent convection prior to coupling.

The climate model is applied to investigate the effect of excess freshwater discharge into the North Atlantic, and the influence of the parameterization of precipitation is tested. The Atlantic thermohaline flow is sensitive to anomalous freshwater input. Reversals of the deep circulation can occur in the Atlantic, leading to a state where deep water is formed only in the Southern Ocean. Depending on the zonality of precipitation, a feedback mechanism is identified that may also trigger the reversal of the Pacific thermohaline circulation yielding the inverse conveyor belt as an additional steady state. In total, four different stable equilibria of the coupled model were realized.
\end{abstract}

\section{Introduction}

For a long time it was believed that climatic change and climate variability are mainly influenced by changes of the seasonality of the solar irradiation and the energy budget at the earth's surface. In fact, much of the paleoclimatic evidence assembled over the past centuries could be consistently explained by the theory of Milankovitch (1941) and their refinements (Berger 1988 ). With the improvement of existing and the advent of new methods of climate reconstruction, it became possible to resolve the climate record more ac-

\footnotetext{
${ }^{\dagger}$ Present affiliation: Lamont-Doherty Geological Observatory of Columbia University, Palisades, New York.

Corresponding author address: Dr. Thomas F. Stocker, Lamont-
oherty Geological Observatory of Columbia University, Palisades,

Corresponding author address: Dr. Thomas F. Stocker, Lamont-
Doherty Geological Observatory of Columbia University, Palisades, NY 10964.
} (C) 1992 American Meteorological Society

curately, both in space and time. While much data quantitatively corroborated Milankovitch's theory, other features defied straightforward explanation. Examples of the latter include (i) the largest signal in the climate records of the Pleistocene, the 100 000-year cycles, (ii) rapid terminations of the last several ice ages, (iii) oscillations during the cold phases of ice ages on time scales of several thousand years, and (iv) climatic "events" such as the Younger Dryas. This suggests that there may be a missing component in our picture of the climate system and that the classical view of the World Ocean as being mainly a passive reservoir of heat must be revised. Consequently, over the last few years the thermohaline circulation of the World Ocean has become one of the focal subjects of climate research in an effort to obtain a more complete understanding of past steady states and rapid transient behavior of the climate.

The main purpose of this paper is to present a coupled ocean-atmosphere climate model of intermediate 
complexity that focuses on the dominant physical processes in the ocean pertaining to the thermohaline circulation and includes a satisfactory coupling with a simple atmospheric model component. By zonally averaging the ocean circulation and yet resolving it longitudinally in three different ocean basins, we demonstrate that it is possible to obtain a present-day steady state with realistic temperature, salinity, overturning, and flux fields. We show that the ocean model closely approximates observations without the introduction of a large number of different parameterizations. Because our emphasis is on very long time scales exceeding decades, we restrict attention to annual-mean conditions and use a classical energy balance model for the atmosphere. The paper is therefore a step toward a complete latitude-depth climate model.

A second purpose is to investigate systematically the stability of the present-day climate in the model. Climate drift in the model is found to be linked to intermittent convection in the North Pacific. Two measures to avoid climate drift are presented in this paper. We then examine the influence of anomalous freshwater discharge into the North Atlantic (as occurred during the termination of the last ice age) and the dependence of the resulting steady state on various model parameters and parameterizations. Since the climate model is so inexpensive to run ( $16 \mathrm{~min}$ of CPU time on an IBM 3090 for 1000 model years), extensive sensitivity studies are feasible. We have deliberately kept the number of parameterizations to an absolute minimum. Thus, the basic dynamics of the coupled model are transparent, and operating feedback processes can be identified relatively easily.

The relevance of the thermohaline circulation to climatic change was dramatically demonstrated by Bryan (1986), who shows, using a three-dimensional BryanCox Ocean General Circulation Model (OGCM), that basinwide circulation changes can occur on time scales of a few hundred years. His study is a confirmation of the relevance of Stommel's (1961) box model, which exhibits two stable states under identical surface forcing. Motivated by these results, researchers have developed various models to investigate the dynamics of the thermohaline circulation. Box models by Rooth (1982) and Welander (1986) consider the global ocean with different flow routes for the deep water, Birchfield (1989) and Birchfield et al. (1990) include atmospheric feedbacks, and Marotzke (1990) studies an AtlanticPacific basin system.

Latitude-depth or zonally averaged models belong to an intermediate level in the hierarchy of climate models. For the atmosphere, several models have been developed. Among the earliest are the energy balance models of Sellers (1969) and Budyko (1969), which have no explicit dynamics. Meridional heat transport in the atmosphere as well as in the ocean is parameterized diffusively in terms of the atmospheric surface temperature. Recognizing the importance of heat stor- age in the deep ocean, Hoffert et al. (1980) proposed an advective-diffusive ocean model with a fixed upwelling rate. Harvey and Schneider (1985a,b) incorporated this ocean model into their energy balance model to investigate the effect of a time-dependent $\mathrm{CO}_{2}$ increase. Neither the ocean nor the atmosphere component contain any dynamics, so results from transient experiments should be interpreted with due caution. Fichefet et al. (1989) use a two-level quasigeostrophic atmosphere in their zonally averaged climate model. Their ocean, however, consists only of a diffusive mixed layer on top of an inactive deep ocean. Thus, to date, no two-dimensional coupled atmosphere-ocean model with ocean dynamics is available.

Marotzke et al. (1988) present a two-dimensional ocean model with steady states similar to the zonal averages of three-dimensional models. With a hemispheric version, Marotzke (1989) found successive events of violent deep-water formation (flushes) that were also observed in his hemispheric OGCM. Using spherical coordinates and an explicit parameterization of the east-west pressure gradient, Wright and Stocker (1991, henceforth WS1) investigated the flow dynamics of a two-dimensional ocean circulation model and identified instability processes leading to the flush. The model was extended to explore the structure and stability of the global thermohaline circulation in the Pacific and Atlantic oceans (Stocker and Wright 199 la,b, henceforth SW1 and SW2). A preliminary study also involved the thermal coupling of the two-dimensional model to a diagnostic energy balance model (Stocker et al. 1991). Wright and Stocker (1992, henceforth WS2) have developed a three-basin, ocean-only version including a well-mixed surface layer and wind stress; this version will be used as the ocean component in the present paper.

Three-dimensional OGCMs and a coupled atmosphere-ocean climate model (AOGCM) further confirm the importance of the deep ocean circulation and its variability under mixed surface boundary conditions; that is, vertical surface heat fluxes are calculated using a Newtonian formulation, while the freshwater fluxes are kept constant. Reexamining Bryan's (1986) experiments, Marotzke (1989) established diffusively dominated states with very weak overturning, which ultimately lead to rapid flushes of the deep ocean. Weaver and Sarachik (1991a) also use the three-dimensional Bryan-Cox model and find flushes recurring on a much shorter time scale of a few hundred years, while their hemispheric version shows decadal fluctuations before reaching a steady state (Weaver and Sarachik 1991b). Variability of the thermohaline circulation is also present in three-dimensional models using a more realistic geometry. Maier-Reimer and Mikolajewicz (1989) show that their global ocean model is extremely sensitive to freshwater anomalies added to the North Atlantic, and deep-water formation can be shut off easily within a few decades. Marotzke and Wil- 
lebrand (1991) established four equilibria in the Pacific-Atlantic version of their Bryan-Cox OGCM; the model in this paper is consistent with these findings. Using a three-dimensional AOGCM, Manabe and Stouffer (1988) find two different states that can be realized under identical forcing. Again, one state exhibits an "active" Atlantic thermohaline circulation with realistic deep-water formation, while in the other state no deep water is formed.

Thus, it is evident that a credible climate model must include a prognostic component for the deep ocean in order to accurately assess oceanic feedbacks to the global climate. In the present paper we provide a climate model of lower complexity, with which extensive sensitivity studies can be undertaken.

We conclude this introduction by mentioning some relevant observational evidence for possible fundamental changes in the ocean circulation. Broecker et al. (1985) studied the spatial distribution of the Younger Dryas climate signal, which is primarily found in regions influenced by the North Atlantic but is absent in records from regions farther away (e.g., central and western North America). They argue that fundamental changes of the Atlantic or even global thermohaline circulation could explain the structure of the climatic record. Based on isotope ratios from deep-sea sediments, Boyle and Keigwin (1987) find that deep-water formation in the Atlantic was reduced during glacial time. This is consistent with the fact that Antarctic bottom water penetrated farther north into the Atlantic than today (Duplessy et al. 1988). Reviewing data from the deep ocean as well as from ice cores and pollen analyses, Broecker and Denton (1989) came to the conclusion that changes in the ocean's thermohaline circulation are necessary to put these findings into a consistent framework.

The paper is organized as follows. In section 2 we describe the climate model; namely, the ocean component (section 2a), the atmosphere component (section $2 \mathrm{~b}$ ), and the objective parameter determination for coupling ( section $2 \mathrm{c}$ ). Section 3 presents the steady state of the climate model for present-day conditions. For certain parameter values a climate drift is observed that could be removed by inhibiting intermittent convection in the model. In section 4 we present the different equilibria found in the coupled model and a sensitivity study for anomalous freshwater discharged into the North Atlantic that models a deglaciation. Conclusions follow in section 5 .

\section{Model description}

The number of climatic processes that can be simulated by a zonally averaged climate model is inherently limited. Therefore, in such a model one cannot include an indiscriminant selection of processes and feedback mechanisms. On the other hand, climate models of lower complexity can be used for extensive sensitivity and process studies and can help us learn more about the interaction of different components of

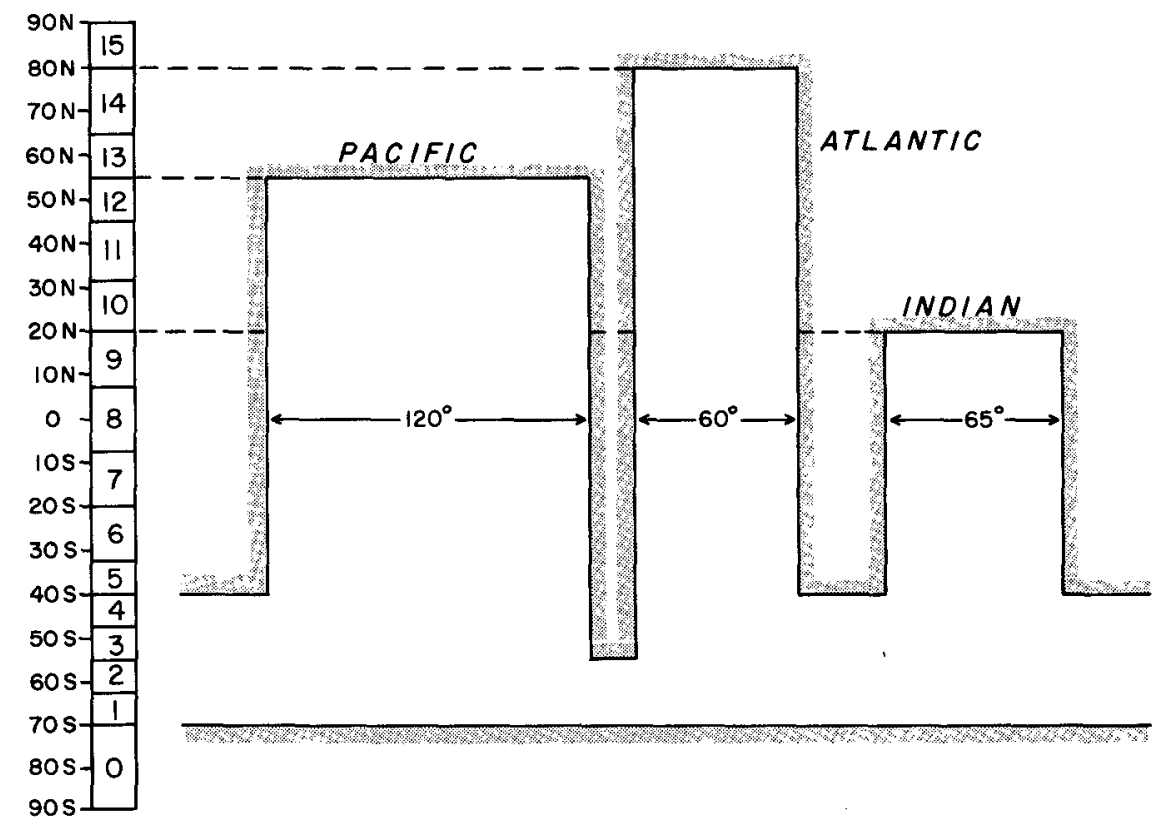

FIG. 1. Geometry of the three zonally averaged ocean basins, joined at $40^{\circ} \mathrm{S}$ to form a Southern Ocean within which properties are mixed zonally. The extension of South America provides for a weak zonal pressure gradient that contributes to the meridional thermohaline circulation. South of $55^{\circ} \mathrm{S}$ no zonal pressure gradient can be established. The latitudinal resolution in the model is indicated by the numbered boxes on the left. 
the climate system. Such models can make contributions to our understanding if they are based on thoroughly understood principles, and if the number of parameterizations is kept to a minimum. We have adopted this philosophy and formulated a self-consistent model that represents today's climate with reasonable accuracy. Multiple equilibria are present, and results compare favorably with those from three-dimensional models.

\section{a. The ocean model}

The basic ocean model was developed by WS1. Here we consider the extended version of the model described by WS2, with a well-mixed surface layer and wind stress in a three-basin geometry (Fig. 1). In order to represent the very different roles the major ocean basins play with respect to the thermohaline circulation, each basin is represented by an individual, zonally averaged domain. The Pacific, Atlantic, and Indian oceans extend to $55^{\circ} \mathrm{N}, 80^{\circ} \mathrm{N}$, and $20^{\circ} \mathrm{N}$, respectively, with corresponding angular widths of $120^{\circ}, 60^{\circ}$, and $65^{\circ}$. Each basin has a constant depth $\mathrm{H}=5000 \mathrm{~m}$ and joins the Southern Ocean at $40^{\circ} \mathrm{S}$, which extends to $70^{\circ} \mathrm{S}$. In the Southern Ocean, temperature and salt are instantly mixed longitudinally to model the effect of the much shorter circulation time scales associated with the Antarctic Circumpolar Current. The east-west pressure gradient is reduced to a negligible value south of $55^{\circ} \mathrm{S}$, since there are no zonal barriers in that region to support a zonally averaged pressure gradient. The model is based on the zonally averaged conservation equations of momentum, mass, heat, and salt, which are given by

TABLE 1. Ocean model parameters.

\begin{tabular}{|c|c|c|}
\hline$f$ & Coriolis parameter & $2 \Omega \sin \phi$ \\
\hline$\Omega$ & angular velocity & $7.27 \times 10^{-5} \mathrm{~s}^{-1}$ \\
\hline$\rho_{*}$ & reference density & $1027.8 \mathrm{~kg} \mathrm{~m}^{-3}$ \\
\hline$a$ & earth's radius & $6371 \mathrm{~km}$ \\
\hline$g$ & gravity & $9.81 \mathrm{~m} \mathrm{~s}^{-2}$ \\
\hline$A$ & $\begin{array}{l}\text { vertical eddy diffusivity for } \\
\text { momentum }\end{array}$ & $10^{-4} \mathrm{~m}^{2} \mathrm{~s}^{-1}$ \\
\hline$K_{\mathrm{H}}$ & $\begin{array}{l}\text { horizontal eddy diffusivity for } \\
\text { temperature and salinity }\end{array}$ & $10^{3} \mathrm{~m}^{2} \mathrm{~s}^{-1}$ \\
\hline$K_{\mathrm{V}}$ & $\begin{array}{l}\text { vertical eddy diffusivity for } \\
\text { temperature and salinity }\end{array}$ & $10^{-4} \mathrm{~m}^{2} \mathrm{~s}^{-1}$ \\
\hline$\epsilon_{0}$ & closure parameter & 0.3 \\
\hline$H$ & ocean depth & $5000 \mathrm{~m}$ \\
\hline$\Delta z$ & mixed-layer depth & $50 \mathrm{~m}$ \\
\hline & bottom of model cells [m] & $\begin{array}{l}50,100,150,250,500 \\
750,1000,1500 \\
2000,2500,3000 \\
3500,4000,4500 \\
5000\end{array}$ \\
\hline$\tau$ & $\begin{array}{l}\text { relaxation time for surface } \\
\text { boundary condition }\end{array}$ & 50 days \\
\hline$C_{o}$ & specific heat capacity of seawater & $3900 \mathrm{~J}(\mathrm{~kg} \mathrm{~K})^{-1}$ \\
\hline$e_{o}$ & ocean surface longwave emissivity & 0.96 \\
\hline
\end{tabular}

$$
\begin{gathered}
-f v=-\frac{1}{\rho_{*} a \cos \phi} \frac{\Delta p}{\Delta \Lambda}+A \frac{\partial^{2} u}{\partial z^{2}} \\
f u=-\frac{1}{\rho_{*} a} \frac{\partial p}{\partial \phi}+A \frac{\partial^{2} v}{\partial z^{2}}, \quad(1 \mathrm{a}, \mathrm{b}) \\
\frac{\partial p}{\partial z}=-g \rho(T, S), \quad \frac{1}{a \cos \phi} \frac{\partial(\cos \phi v)}{\partial \phi}+\frac{\partial w}{\partial z}=0 \\
\frac{\partial T}{\partial t}+\frac{1}{a \cos \phi} \frac{\partial(\cos \phi v T)}{\partial \phi}+\frac{\partial(w T)}{\partial z} \\
=\frac{1}{a^{2} \cos \phi} \frac{\partial}{\partial \phi}\left(\cos \phi K_{H} \frac{\partial T}{\partial \phi}\right)+\frac{\partial}{\partial z}\left(K_{V} \frac{\partial T}{\partial z}\right)+q_{T}^{\text {conv }} \\
\frac{\partial S}{\partial t}+\frac{1}{a \cos \phi} \frac{\partial(\cos \phi v S)}{\partial \phi}+\frac{\partial(w S)}{\partial z} \\
=\frac{1}{a^{2} \cos \phi} \frac{\partial}{\partial \phi}\left(\cos \phi K_{H} \frac{\partial S}{\partial \phi}\right)+\frac{\partial}{\partial z}\left(K_{V} \frac{\partial S}{\partial z}\right)+q_{S}^{\text {conv }}
\end{gathered}
$$

where all quantities are zonal averages, $(\phi, z)$ are the latitude-depth coordinates with $z$ positive upward, $a$ is the radius of the earth, $(u, v, w)$ is the velocity field, $f$ is the Coriolis parameter, $\rho_{*}$ is a constant density, $p$ is pressure, $\Delta p$ is the east-west pressure difference, $\Delta \Lambda$ is the angular width of the basin, $A$ is a constant eddy viscosity, $g$ is gravity, $\rho(T, S)$ is density given by a nonlinear equation of state (Gill 1982, p. 599, A3.2), $T$ and $S$ are temperature and salinity, $K_{H}$ and $K_{V}$ are constant horizontal and vertical diffusivities, and $q_{T}^{\text {conv }}$ and $q_{s}^{\text {conv }}$ represent the influence of convection on heat and salt. The values for the different parameters are summarized in Table 1.

Several approximations are incorporated in (1)-(4). Time-dependent and nonlinear terms in the momentum balances ( $1 \mathrm{a}$ ) and (1b) are neglected and, together with the hydrostatic assumption in (2a), this results in momentum equations that are diagnostic. Boussinesq and rigid-lid approximations are also invoked. Time dependence is thus only present in the advection-diffusion equations for $T$ and $S$, which are coupled to the dynamics via the equation of state. In the zonal average, we have also neglected meridional heat and salt transport due to gyre circulations. Bryden and Hall (1980) note that most of the Atlantic heat flux is due to barotropic northward flow through the Straits of Florida Strait and assume that the Atlantic basin is entirely closed north of $25^{\circ} \mathrm{N}$. They argue that the compensating return flow at a lower temperature is also barotropic, implying only little importance of meridional heat flux by the thermohaline (baroclinic) circulation. Hall and Bryden (1982) state that both barotropic and baroclinic mechanisms are plausible interpretations of the available data. Other observational estimates from 
the Atlantic Ocean using inverse methods (Roemmich 1980 ) as well as direct measurements (Rago and Rossby 1987) suggest that meridional overturning is the dominant process for meridional heat flux in the Atlantic. This is also supported by the inverse modeling study of Wunsch (1984) and analyses from three-dimensional OGCMs (Bryan 1987; Bryan and Holland 1989). However, gyre circulations may contribute significantly to the heat flux in other regions (Fu 1986), but this effect is not modeled here.

In the zonally averaged $u$-momentum equation, the east-west pressure difference $\Delta p$ must be parameterized in order to close the system of equations. Combining the considerations in WS1 and SW1, a consistent parameterization is given by

$$
\Delta \rho=-\epsilon_{0} \frac{\pi}{3} \sin 2 \phi \frac{\partial \rho}{\partial \phi},
$$

where $\epsilon_{0}=0.3$ is a constant closure parameter measuring the ageostrophy of the zonal velocity field in a $60^{\circ}$-wide basin. With $\Delta \rho$ given by (5), $\Delta p$ is determined by the hydrostatic relation ( $2 a)$ and the condition that there be no depth-integrated meridional volume transport across any latitude in each basin. Analysis of the steady-state thermohaline circulation in an OGCM has confirmed the above parameterization (WS1). In order to crudely account for the absence of zonal pressure gradients south of $55^{\circ} \mathrm{S}$, we set $\epsilon_{0}=0.0001$ there.

The flow is driven by momentum and buoyancy fluxes at the surface of the ocean. For the ocean-only model, buoyancy fluxes are at first calculated from the usual restoring boundary conditions given by

$$
\begin{aligned}
& -K_{V} \frac{\partial T}{\partial z}=\frac{\Delta z}{\tau}\left(T-T^{*}\right), \\
& -K_{V} \frac{\partial S}{\partial z}=\frac{\Delta z}{\tau}\left(S-S^{*}\right),
\end{aligned}
$$

where $\tau$ is a relaxation time scale representative of the mixed-layer depth $\Delta z$, and $T^{*}$ and $S^{*}$ are the zonal averages of temperature and salinity at $30-\mathrm{m}$ depth as given by Levitus (1982, Tables 16-42). At steady state we switch to the more realistic mixed boundary conditions given by

$$
-K_{V} \frac{\partial T}{\partial z}=\frac{\Delta z}{\tau}\left(T-T^{*}\right), \quad-K_{V} \frac{\partial S}{\partial z}=Q_{S}^{*},
$$

where $Q_{S}^{*}$ is a time-independent salt flux diagnosed from the steady state obtained under (6).

Many studies using two- and three-dimensional OGCMs have shown that mixed boundary conditions allow for multiple equilibria, transient behavior, and natural variability of the thermohaline circulation (Bryan 1986; Marotzke 1989; Weaver and Sarachik 1991a,b; WS1; SW 1; SW2). Although for ocean-only models (7) is a reasonable boundary condition for climate-related studies, in reality both temperature and salinity at the ocean surface are free to adjust and must be determined by appropriate $f l u x$ boundary conditions. These will be described in the next section.

The system is completed with the surface boundary conditions for the velocities and the lateral and bottom boundary conditions for the various fields:

$$
\begin{aligned}
A \frac{\partial u}{\partial z} & =\frac{\tau^{\lambda}}{\rho_{*}}, \quad A \frac{\partial v}{\partial z}=0, \quad w=0 \quad \text { at } \quad z=0 \\
A \frac{\partial u}{\partial z} & =0, \quad A \frac{\partial v}{\partial z}=0, \quad w=0 \quad \text { at } \quad z=-H, \\
\frac{\partial T}{\partial z} & =0, \quad \frac{\partial S}{\partial z}=0 \quad \text { at } \quad z=-H, \\
\frac{\partial T}{\partial \phi} & =0, \quad \frac{\partial S}{\partial \phi}=0 \quad \text { at } \phi=\phi_{0}, \phi_{1},
\end{aligned}
$$

where $\tau^{\lambda}$ denotes the zonal component of wind stress (Han and Lee 1983). No-stress and no-flux conditions are applied at the bottom and at the southern and northern boundaries at latitudes $\phi_{0}$ and $\phi_{1}$, respectively.

Equations (1)-(4) can be combined into an equation for the meridional overturning streamfunction $\Psi$ defined by

$$
v=-\frac{1}{\cos \phi} \frac{\partial \Psi}{\partial z}, \quad w=\frac{1}{a \cos \phi} \frac{\partial \Psi}{\partial \phi} .
$$

The streamfunction is determined by vertical integrals of the meridional density gradients (see WS1 for details). From (12) the velocity components are calculated and the time-dependent advection-diffusion equations for $T$ and $S$ are solved using forward differencing in time and the numerical scheme of Fiadeiro and Veronis (1977) with spatially varying grid resolution (Wright 1992). The horizontal resolution is indicated in Fig. 1, and for the vertical discretization we select 15 layers with decreasing resolution in the deeper ocean (Table 1). To obtain a steady ocean circulation, we spin up from rest with uniform temperature and salinity fields, with the restoring boundary conditions (6) and the observed zonal averages $T^{*}$ and $S^{*}$ of Levitus (1982). After 5000 years (a longer time may be required for reduced $K_{H}$ and $K_{V}$ ), the state is essentially steady. From this time onward, the mixed boundary conditions (7) are selected using the diagnosed vertical salt flux from $t=5000 \mathrm{yr}$. Provided a steady state is reached, the circulation remains stable under mixed boundary conditions. The ocean model can now be coupled to the atmospheric component from which time onward flux boundary conditions on both temperature and salt determine exchanges between atmosphere and ocean.

\section{b. The energy balance model of the atmosphere}

As pointed out above, the emphasis of the present model is the thermohaline circulation of the global 
ocean and the various feedback mechanisms that influence the surface air temperature and atmospheric heat fluxes during possible ocean mode changes. We are concerned with climatic evolution on long time scales, and thus the seasonal cycle is not modeled in the present version. Neither vertical nor longitudinal structure in the atmosphere are resolved. Furthermore, processes related to land surfaces (vegetation, snow) and high latitudes (sea ice) are not taken into account. The present paper therefore explores the first step in devising a fully coupled latitude-depth climate model. Processes such as the meridional flux of sensible heat, potential energy, and the longwave radiation to outer space are parameterized in terms of the surface air temperature. The longitudinal resolution associated with the three ocean basins will introduce some longitudinal dependence to certain parameters for the energy balance model. This is explained in section 2c. form

$$
\begin{aligned}
\rho_{A} C_{A} \frac{\partial T_{A}}{\partial t}=-\frac{1}{a \cos \phi} \frac{\partial}{\partial \phi} & \left(\cos \phi F^{\text {merid }}\right) \\
& -\frac{1}{H_{A}}\left(F^{\text {toa }}-F^{\text {ocean }}\right),
\end{aligned}
$$

where $\rho_{A}$ is a constant surface air density, $C_{A}$ the specific heat capacity of air, $T_{A}$ the surface air temperature, $F^{\text {merid }}$ the meridional flux of heat, $H_{A}$ a scale height of the atmosphere, and $F^{\text {toa }}$ and $F^{\text {ocean }}$ are the vertical fluxes of heat through the top of the atmosphere and the ocean surface (positive upward). The values of various parameters required by the atmospheric model are given in Table 2. For the meridional heat flux we use the standard linear parameterization with a latitude-dependent eddy diffusivity $K_{A}$ :

$$
F^{\text {merid }}=-\frac{\rho_{A} C_{A} K_{A}}{a} \frac{\partial T_{A}}{\partial \phi}
$$

TABLE 2. Atmospheric model parameters; those marked with $\dagger$ are determined by observations and the steady state of the ocean.

\begin{tabular}{lll}
\hline \hline$\rho_{A}$ & surface air density & $1.225 \mathrm{~kg} \mathrm{~m}^{-3}$ \\
$C_{A}$ & specific heat capacity of dry air & $1004 \mathrm{~J}\left(\mathrm{~kg} \mathrm{~K}^{-1}\right.$ \\
$H_{A}$ & scale height & $8320 \mathrm{~m}$ \\
$\sigma$ & Stefan-Boltzmann constant & $5.67 \times 10^{-8} \mathrm{~W}\left(\mathrm{~m}^{2} \mathrm{~K}^{4}\right)^{-1}$ \\
$\kappa$ & absorptivity of shortwave radiation & 0.2857 \\
$D$ & transfer coefficient of sensible heat & $10 \mathrm{~W}\left(\mathrm{~m}^{-2} \mathrm{~K}\right)^{-1}$ \\
$L$ & latent heat of evaporation & $2.5 \times 10^{6} \mathrm{~J} \mathrm{~kg}^{-1}$ \\
$S_{*}$ & reference salinity & $35 \mathrm{psu}$ \\
$K_{A}$ & horizontal eddy diffusivity ( $\dagger)$ & $4 \times 10^{5}-3 \times 10^{7} \mathrm{~m}^{2} \mathrm{~s}^{-1}$ \\
& & $(\mathrm{Fig} .8 \mathrm{a})$ \\
$e_{P}$ & planetary emissivity ( $\dagger)$ & $0.55-0.72(\mathrm{Fig} .8 \mathrm{~b})$ \\
$e_{A}$ & atmospheric emissivity & $0.60-0.96(\mathrm{Fig} .8 \mathrm{~b})$ \\
& (downwelling) $\dagger$ & \\
$c_{E}$ & bulk coefficient of evaporation $\dagger$ & $5 \times 10^{3}-10^{5} \mathrm{~W} \mathrm{~m}^{-2}$ \\
\hline
\end{tabular}

This approximation is reasonable provided length and time scales are of order $10^{6} \mathrm{~m}$ and $1 \mathrm{yr}$ or longer (Lorenz 1979). We apply a no-flux boundary condition, $F^{\text {merid }}=0$, at the poles. At the top of the atmosphere, the net upward heat flux consists of the longwave radiation to space less the incoming net shortwave radiation $Q^{\text {short }}$, taken to be time independent in this paper. The former is parameterized by greybody radiation in terms of the surface air temperature, using a latitude-dependent planetary emissivity $e_{P}$. Thus, $F^{\text {toa }}$ is given by

$$
F^{\text {taa }}=\sigma e_{P} T_{A}^{4}-Q^{\text {short }} .
$$

The interaction with the ocean is incorporated in $F^{\text {ocean }}$ in (13) and takes the form

$$
F^{\text {ocean }}=\sum_{\text {basins }} \frac{\Delta \Lambda}{2 \pi}\left(F^{\mathrm{OA}}+P-E\right),
$$

where $P$ and $E$ are in watts per square meter in this formulation [this can be readily converted to $\mathrm{m} \mathrm{yr}^{-1}$ by multiplying it with $365.25 \times 86400 /\left(L \rho_{*}\right)=1.23$ $\times 10^{-2} \mathrm{~m}^{3}(\mathrm{~W} \mathrm{yr})^{-1}$, where $L$ is the latent heat of evaporation ]. Each ocean basin with longitudinal extent $\Delta \mathbf{\Lambda}$ contributes to the total vertical heat flux by the vertical ocean-to-atmosphere heat flux $F^{\mathrm{OA}}$, and the divergence of the meridional flux of latent heat fluxes associated with precipitation $P$ and evaporation $E$. Note that for convenience the meridional flux of latent heat, which should be part of $F^{\text {merid }}$, is directly included in $F^{\text {ocean }}$. Thus, $F^{\text {merid }}$ comprises the meridional flux of sensible heat and potential energy, while the divergence of meridional latent heat flux is handled separately in $F^{\text {ocean }}$. The combination of sensible heat and potential energy fluxes into a single term is consistent with the fact that, under the hydrostatic approximation, the depth-integrated potential energy is proportional to the depth-integrated internal energy (Holton 1979).

The ocean-to-atmosphere heat flux and the temperature-dependent evaporation are given by

$$
\begin{aligned}
& F^{\mathrm{OA}}=-(1-\kappa) Q^{\text {short }}+\sigma e_{O} T^{4} \\
& \quad-\sigma e_{A} T_{A}^{4}+D\left(T-T_{A}\right)+E, \\
& E=c_{E} e^{\left(14.7-(5418 \mathrm{~K}) / T_{A}\right)}\left\{0.2+(5418 \mathrm{~K}) \frac{T-T_{A}}{T_{A}^{2}}\right\},
\end{aligned}
$$

where $\kappa=20 / 70$ (Peixóto and Oort 1984) is a constant atmospheric absorptivity, $e_{O}=0.96$ (Isemer and Hasse 1987 ) and $e_{A}$ (objectively estimated in section 2c) are oceanic and atmospheric emissivities, and $D=10 \mathrm{~W}$ $\left(\mathrm{m}^{2} K\right)^{-1}$ is a constant transfer coefficient for sensible heat (Haney 1971). In addition, we also consider a simplified form of (17) by taking $e_{O}=e_{A}=1$. The temperature dependence of evaporation is taken from 
Haney (1971), and $c_{E}$ is a bulk aerodynamic constant that will be determined using observations.

From (17) the interaction with the ocean is obviously represented by temperature differences between ocean and the atmosphere. There is, however, a second, equally important coupling between the two components due to the hydrological cycle: $P-E$ is associated with a net flux of freshwater into the ocean and thus contributes to the buoyancy flux that drives the thermohaline circulation. The relation between the virtual salt flux $Q_{S}^{*}$ and $P-E$ is approximated by

$$
P-E=\frac{L \rho_{*}}{S_{*}} Q_{S}^{*},
$$

where $S_{*}$ is a reference salinity. If the ocean-only model is at steady state, the integral of $Q_{S}^{*}$, and hence $P-E$, over the global ocean vanishes. When the ocean and atmosphere components are first coupled, (17) and (19) determine both $E$ and $P$. Note that, at this time, $P-E$, and hence the zonal mean meridional latent heat transport in the atmosphere is determined entirely by the steady state of the ocean-only model. After coupling the buoyancy flux driving the ocean circulation is given by

$$
\begin{aligned}
& -K_{V} \frac{\partial T}{\partial z}=\frac{1}{\rho_{*} C_{O}} F^{\mathrm{OA}}, \\
& -K_{V} \frac{\partial S}{\partial z}=\frac{S_{*}}{L \rho_{*}}(P-E),
\end{aligned}
$$

where $C_{O}$ is the specific heat capacity of water. Note that sea surface temperature and salinity can thus freely adjust to perturbations. Equations (20) constitute the full flux boundary conditions applied in the coupled mode.

Since evaporation depends on the temperature difference between atmosphere and ocean, any subsequent changes in the thermohaline circulation can cause changes in evaporation and in the meridional freshwater flux, whose divergence is proportional to $P$ $-E$. The coupled system is closed if we provide an evolution equation for the precipitation $P$. We are not considering a separate atmospheric water vapor balance, and thus it is consistent to assume no storage of water in the atmosphere; that is, at any time

$$
\sum_{\text {basins }} \Delta \Lambda \int_{\phi_{0}}^{\phi_{1}}(E-P) \cos \phi d \phi=0 .
$$

The question now arises how any excess precipitation should be distributed over the globe when there is no explicit dynamics in the atmospheric model component. It is here that a somewhat ad hoc parameterization is proposed. We will show that its quantitative form is influential in determining the final steady states of the coupled climate model in perturbation experi- ments. We assume that the local rate of change of precipitation is given by

$$
\frac{\partial P}{\partial t}=\left(1-\eta_{Z}\right) \frac{\partial E}{\partial t}+\eta_{Z}\left\langle\frac{\partial E}{\partial t}\right\rangle,
$$

where $\eta_{Z}$ is a constant between 0 and 1 reflecting the zonality of the distribution of excess precipitation; the zonal average over the three basins is indicated by \langle\rangle . Note that $\eta_{Z}=0$ corresponds to local compensation. From an oceanic viewpoint, this is equivalent to the mixed boundary conditions (7) used in the ocean-only mode when the net freshwater flux through the ocean surface is fixed everywhere. For $\eta_{Z}=1$, excess precipitation is uniformly distributed over the ocean in a latitude band. The analysis by Zaucker and Broecker (1992) using the Oort (1983) climatology suggests that the present-day annually averaged water vapor fluxes are predominantly in the zonal direction. Here we assume that this is strictly true for perturbations (i.e., $\partial\langle P-E\rangle / \partial t=0$ ). Thus, Eq. (22) implies that the zonal mean meridional latent heat transport does not change even during transient adjustments and remains fixed at the values obtained at the time of coupling (i.e., the zonal mean meridional latent heat flux always reflects present-day climatic conditions).

The hydrological cycle in the atmosphere is notoriously difficult to simulate properly in a climate model. What we have proposed is the most rudimentary scheme consistent with the concept of an energy balance model and present-day observations. Our approach differs from previous work. In their one-dimensional energy balance models, Sellers (1969) parameterizes meridional flux of latent heat in terms of surface air temperature, while Harvey (1988) considers a swamp surface and obtains the vertical flux of latent heat by relaxing specific humidity to the saturation value. The relaxation constant depends on the surface type. Zonally averaged atmospheric models with vertical resolution also use a swamp surface (Held and Suarez 1978; Vallis 1982) or prescribe relative humidity from climatology (Fichefet et al. 1989). Where precipitation is predicted, qualitative agreement with observations is achieved (Vallis 1982; MacCracken and Ghan 1988), but the models generally yield overestimates. Due to the lack of satisfactory schemes, we therefore decided to adopt the most straightforward formulation consistent with the steady-state freshwater fluxes in the ocean.

For the numerical solution of (13), centered differences in space and forward differencing in time are used on a horizontal grid coinciding with that of the ocean but extending to both poles. Comparing the CFL criteria of the ocean and the atmosphere, one finds that maximum allowable time steps in the atmosphere are smaller by about a factor of 50 , reflecting the different thermal inertias. During a coupled run, we thus 
integrate the atmospheric component for 50 time steps without updating the surface fields of the ocean. In practice, the atmosphere remains in quasi-steady equilibrium with the ocean. A transient experiment where the ocean was updated at every atmosphere time step yielded identical results.

\section{c. Determination of the various parameters}

A number of parameters that are representative of the present climate have to be determined. The objective is to use available data in conjunction with the steady state of the ocean model to find the latitudedependent values of the following parameters:

$Q^{\text {short }}(\phi), \quad K_{A}(\phi), \quad e_{P}(\phi), \quad e_{A}(\phi, i), \quad c_{E}(\phi, i)$,

where $i \in\{A, P, I\}$ is an index denoting the Atlantic, Pacific, or Indian basin. The procedure requires the values

$$
F^{\text {merid }}(\phi), \quad T_{A}(\phi), \quad E(\phi, i),
$$

at the initial time of coupling. Any time dependence that might occur in the parameters (23) is not considered in this paper.

The objective determination of the parameters for the present climate starts with the planetary emissivity, $e_{P}$, using the zonal and annual mean values of the emitted longwave flux from Stephens et al. (1981, Table $4 a)$ and the surface air temperature over sea from Oort (1983, Tables 25a and 25b). From Stephens et al. Table $4 c$ and (15), we obtain $Q^{\text {short }}$, which already includes the reduction of the shortwave radiation due to planetary albedo. Here we deviate from Sellers (1969) and others who considered a temperature-dependent albedo to account for varying snow and ice cover. We thus exclude multiple equilibria in the atmosphere (e.g., the small ice cap instability or deep-freeze state); such effects can be consistently modeled only by formulating an appropriate ice sheet model as a third component. This will be done at a later stage.

Next, we determine the eddy diffusivity for the meridional heat flux $F^{\text {merid }}$ in the atmosphere. Substituting (14) and (16) into the steady version of (13) and using (19) yields

$$
\begin{aligned}
& K_{A}(\phi)=\frac{a^{2}}{H_{A} \rho_{A} C_{A} \cos \phi \frac{\partial T_{A}}{\partial \phi}} \\
& \times \int_{-90^{\circ}}^{\phi}\left[F^{\mathrm{toa}}-\sum_{\text {basin }} \frac{\Delta \Lambda}{2 \pi}\left(F^{\mathrm{OA}}+\frac{L \rho_{*}}{S_{*}} Q_{S}^{*}\right)\right] \cos \phi d \phi,
\end{aligned}
$$

where the right side is completely determined by the steady state of the ocean model and the data of Oort (1983) and Stephens et al. (1981). Note that at the instant of coupling, $F^{\mathrm{OA}}$ can be related to the oceanto-atmosphere steady-state heat flux in (6a) by

$$
F^{\mathrm{OA}}=\rho_{*} C_{O} \frac{\Delta z}{\tau}\left(T-T^{*}\right) .
$$

The determination of the atmospheric eddy diffusivity according to (25) implies that $F^{\text {merid }}$ in (14) includes all those meridional energy fluxes that are necessary to balance the oceanic heat fluxes with the flux divergence at the top of the atmosphere. Specifically, $F^{\text {merid }}$ is the sum of the fluxes of sensible heat plus potential energy plus any subgrid-scale contribution.

We now estimate the parameters $e_{O}, e_{A}$, and $c_{E}$ on the right side of (17). For the simplified parameterization with $e_{O}=e_{A}=1$, substitution of (18) into (17) yields directly the bulk aerodynamic coefficients $c_{E}$ as functions of latitude and basin. For the more realistic parameterization (greybody radiation for the longwave fluxes between atmosphere and ocean ) we require additional data. Solving (17) for the atmospheric emissivity for downwelling longwave radiation, we obtain

$$
\begin{aligned}
e_{A}=\frac{1}{\sigma T_{A}^{4}}(- & F^{\mathrm{OA}}-(1-\kappa) Q^{\text {short }} \\
& \left.+\sigma e_{O} T^{4}+D\left(T-T_{A}\right)+E^{\mathrm{obs}}\right),
\end{aligned}
$$

where the right side is known using the evaporation rates $E^{\text {obs }}$ for the three different ocean basins (Baumgartner and Reichel 1975, Table V). The coefficients $c_{E}$ follow from (18). Finally, the procedure also provides us with precipitation over each ocean basin as a function of latitude using (19).

The above approach differs from previous studies in that we do not attempt to formulate further parameterizations of the bulk aerodynamic coefficients $c_{E}$ and atmospheric emissivity that may be functions of wind speed, vertical stability and drag coefficients, and cloud cover and water vapor pressure, respectively. Since such quantities are not predicted as independent variables in the model, a self-consistent procedure introducing as few parameterizations as possible is preferred. Note that if either the observational data or the predictions of the ocean model are poor, some of the coefficients will be poorly determined as well. However, using the described procedure, no inconsistencies, such as unrealistic or even negative emissivities, negative atmospheric diffusivities, or bulk aerodynamic coefficients, were encountered at any latitude.

\section{Present-day simulations}

\section{a. Steady state}

As an example of the model's ability to simulate the present-day climate, we have spun up the ocean from rest for 5000 years in the basin geometry of Fig. 1, using the restoring boundary conditions (6) with $T^{*}$ 


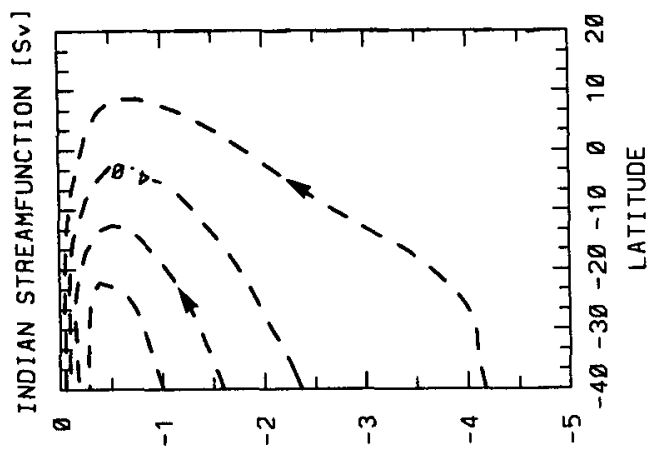

[wy] HLdJO
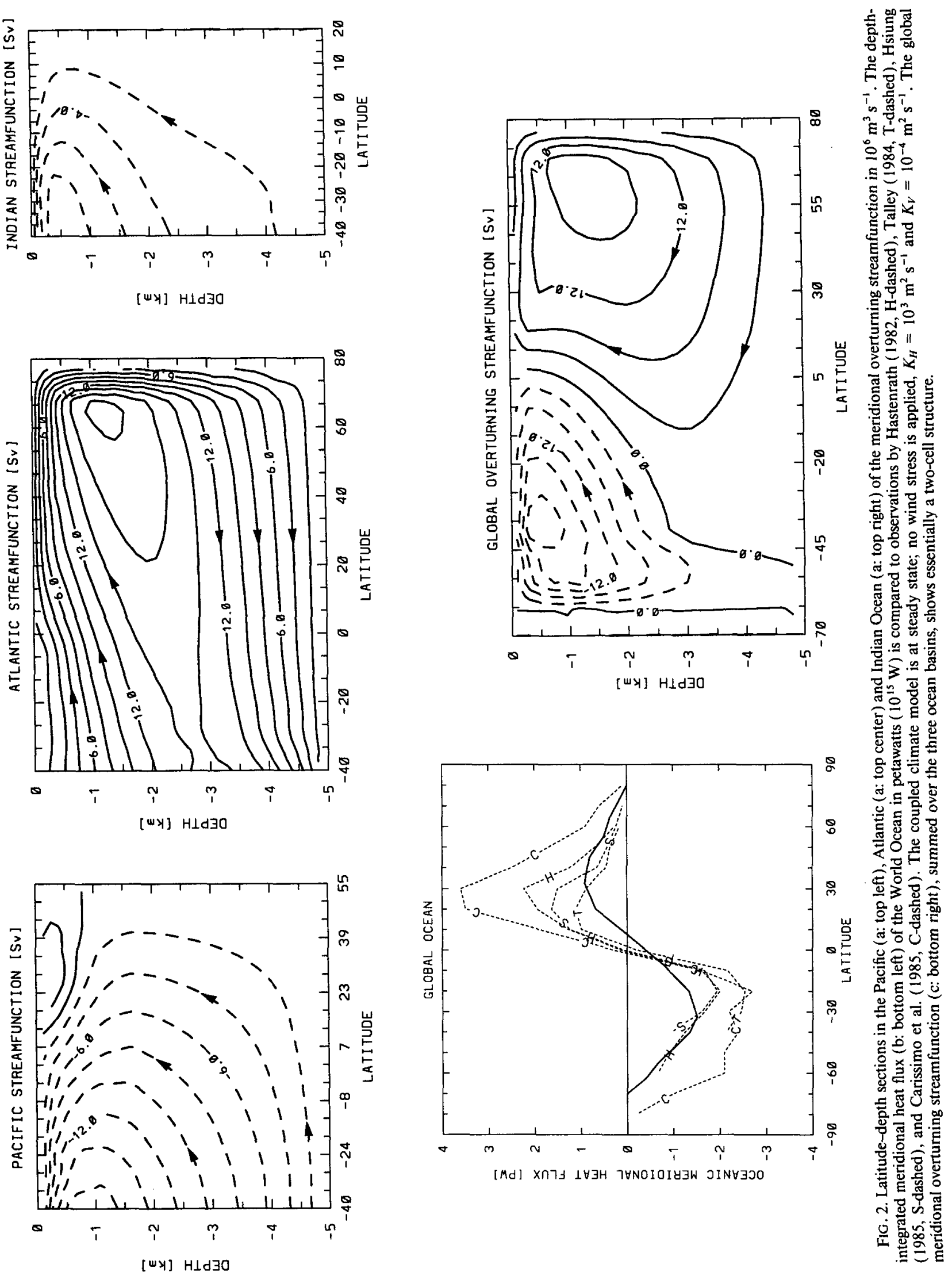
PACIFIC STREAMFUNCTION [Sv]

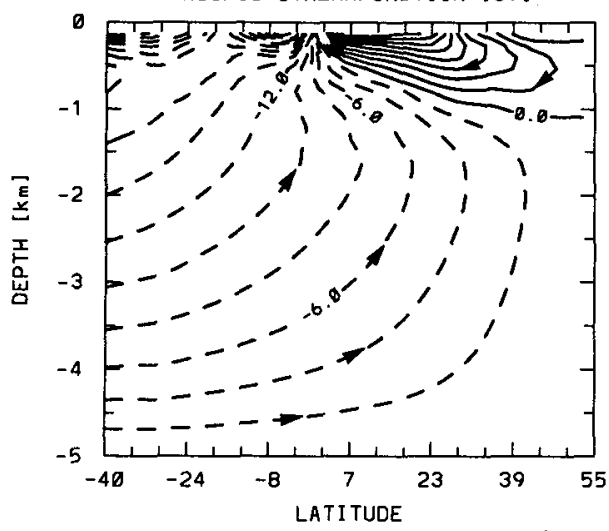

PACIFIC TEMPERATURE $(\operatorname{dog} C)$

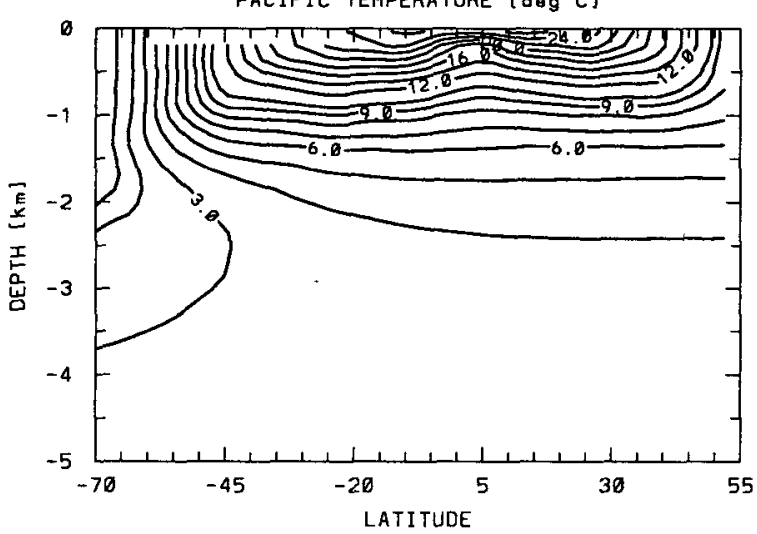

PACIFIC SALINITY [PSU]

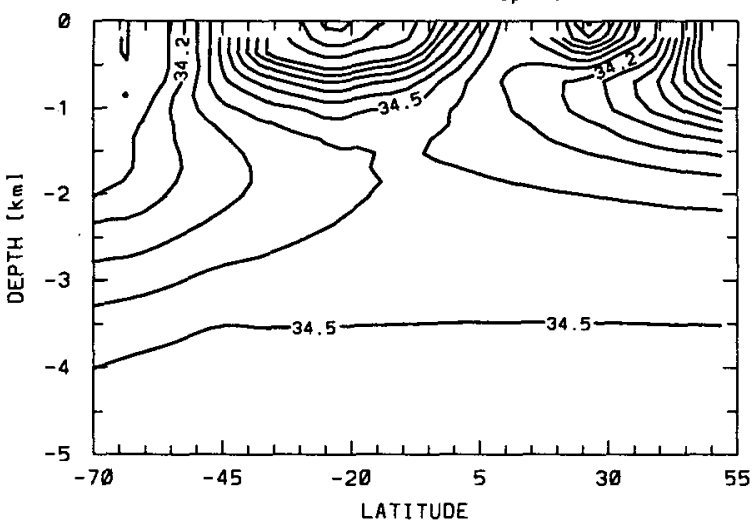

ATLANTIC STREAMFUNCTION [Sv]
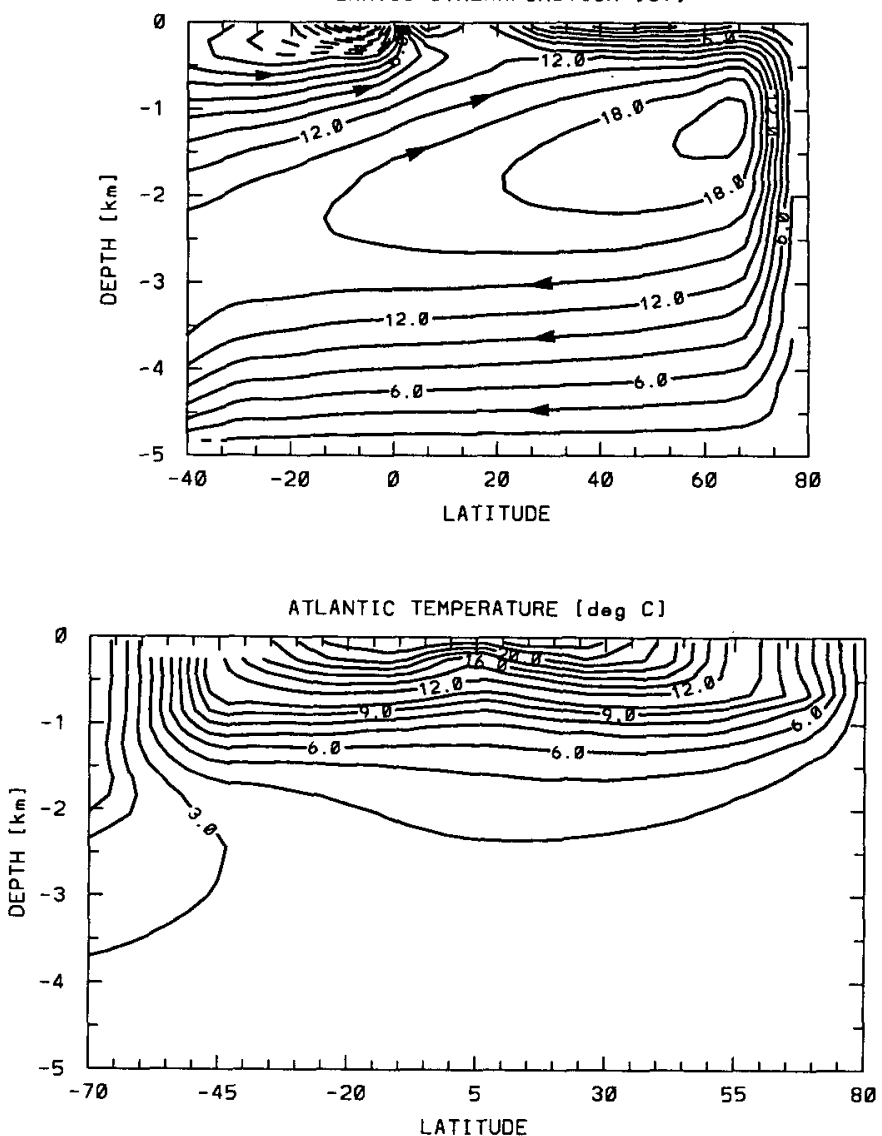

ATLANTIC SALINITY [psu]

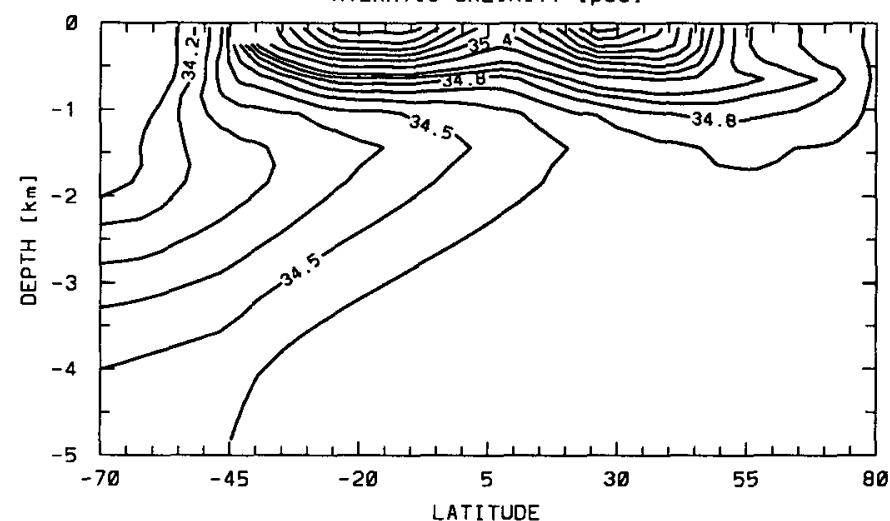

FIG. 3. Latitude-depth sections in the Pacific (a: top left), Atlantic (a: top center) and Indian Ocean (a: top right) of the meridional overturning streamfunction in $10^{6} \mathrm{~m}^{3} \mathrm{~s}^{-1}$, temperature (b: middle row) and salinity in practical salinity units (c: bottom row). The coupled climate model is at steady state; a zonal wind stress (Han and Lee 1983) is applied at the surface, $K_{H}=10^{3} \mathrm{~m}^{2} \mathrm{~s}^{-1}$ and $K_{V}=10^{-4} \mathrm{~m}^{2} \mathrm{~s}^{-1}$.

and $S^{*}$ from Levitus (1982) and the parameter values given in Tables 1 and 2 , and neglecting wind stress. We then switch boundary conditions to (7) and add a 0.3-psu salt anomaly to the northernmost Atlantic cell to check stability of the steady state. Only minor ad- justments occur, and the circulation remains steady over the next 3000 years. Finally, the atmospheric parameters are determined following the procedure in section $2 \mathrm{c}$, and the model is integrated in the coupled mode for another 1000 years. No climate drift is ob- 

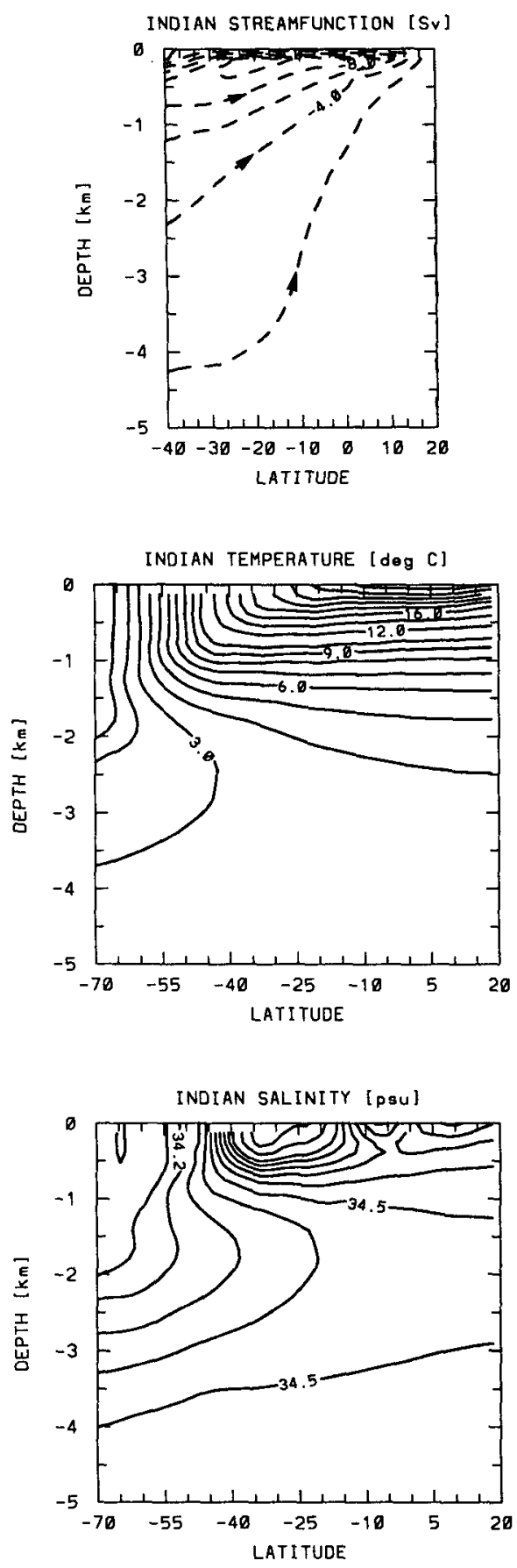

FIG. 3. (Continued)

served for the present parameters, and the global energy imbalance at the top of the atmosphere decreases steadily to $3 \times 10^{-3} \mathrm{~W} \mathrm{~m}^{-2}$ at 9000 years.

Contours of the meridional overturning streamfunction for the three ocean basins are shown in Fig. 2a. Deep water is formed at a rate of $18.3 \mathrm{~Sv}$ ( $1 \mathrm{~Sv}$ $\equiv 10^{6} \mathrm{~m}^{3} \mathrm{~s}^{-1}$ ) north of $60^{\circ} \mathrm{N}$ in the North Atlantic only, while the Pacific and Indian oceans show broad upwelling. This is consistent with SW 1, where the conveyor belt circulation (Gordon 1986) was obtained under idealized surface forcing in an ocean-only model. This situation remains unchanged in the fully coupled model with realistic surface forcing and the Indian Ocean included. The global oceanic meridional heat flux is poleward in both hemispheres and in fair agreement with observational estimates (Fig. 2b). The heatflux divergence in the equatorial regions will increase if wind stress is included. This is discussed in detail by WS2 and shown below (Fig. 6b). Figure $2 \mathrm{c}$ gives the thermohaline circulation summed over the three ocean basins. In agreement with observations, deep water is formed in the North Atlantic and in the Southern Ocean (Warren 1981), and the global thermohaline circulation consists of basically two cells. However, this should not be taken as a justification for approximating the World Ocean by a single basin as done by earlier investigators (Hoffert et al. 1980; Harvey and Schneider 1985a,b; Stocker et al. 1991). In such a World Ocean, large overturning rates of order $50 \mathrm{~Sv}$ are necessary to obtain the correct magnitude of the meridional heat flux. Further, the single-basin approximation not only precludes different steady states possible in a multibasin model, but also completely changes the sensitivity of the coupled climate model. Thus, even in a simplified climate model, some longitudinal resolution of the World Ocean must be incorporated.

The previous experiment is repeated, with the only difference being the inclusion of a zonal wind stress, and the complete diagnosis is given in Figs. 3 to 6. Again, a steady state of the coupled model is reached. As expected from earlier studies (e.g., Bryan and Lewis 1979), the major differences are limited to the upper $500 \mathrm{~m}$ ( represented by five layers in the model). Ekman transport now produces the strongest overturning transport in the model at rates of about $-35 \mathrm{~Sv}$ in the South Pacific at $-10^{\circ} \mathrm{S}$ (Fig. 3a). North of the equator Ekman overturning substantially increases the formation of North Pacific intermediate water and also enhances North Atlantic deep-water formation, now about 20.6 Sv. Wind stress also causes the doming of isotherms around the equator (Fig. 3b), while the effects on the salinity field are minor (Fig. 3c). However, the overall structure of the global thermohaline circulation is not altered, still showing deep-water formation in the Atlantic and upwelling in the Pacific and Indian oceans.

The global conveyor belt is a robust feature of the two- and three-basin ocean-only model as well as of the coupled model. This is also demonstrated by a further experiment starting from the fully spunup steady state of the coupled model illustrated in Fig. 2. Temperature in the atmosphere and the ocean and salinity were then abruptly reset to uniform values of $7^{\circ} \mathrm{C}$ and 34.7 psu, respectively. At the beginning of this experiment, the ocean was thus at rest, and no heat was transported meridionally in the atmosphere. The run 
$\left[\tau^{W / M]} \times \cap 7 \unlhd \perp \forall \exists H \quad \exists \forall \exists H d S O W \perp \forall-O \perp-N \forall \exists J O\right.$

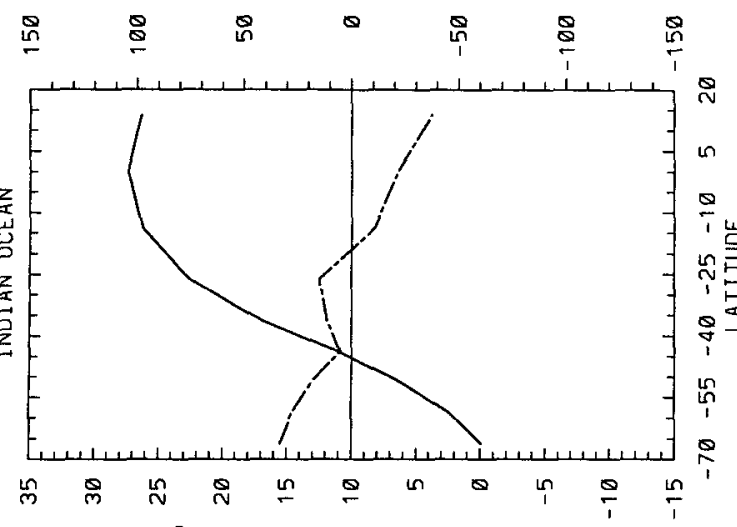

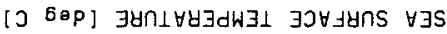

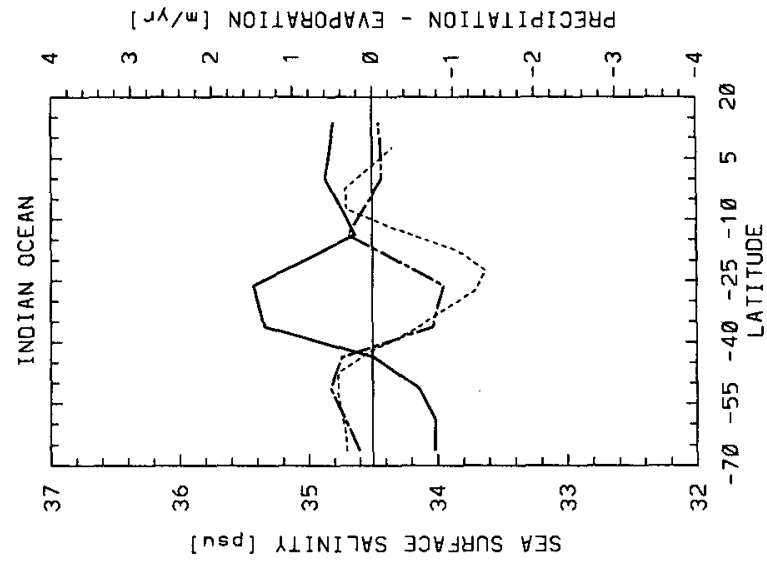

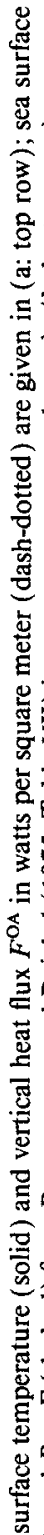
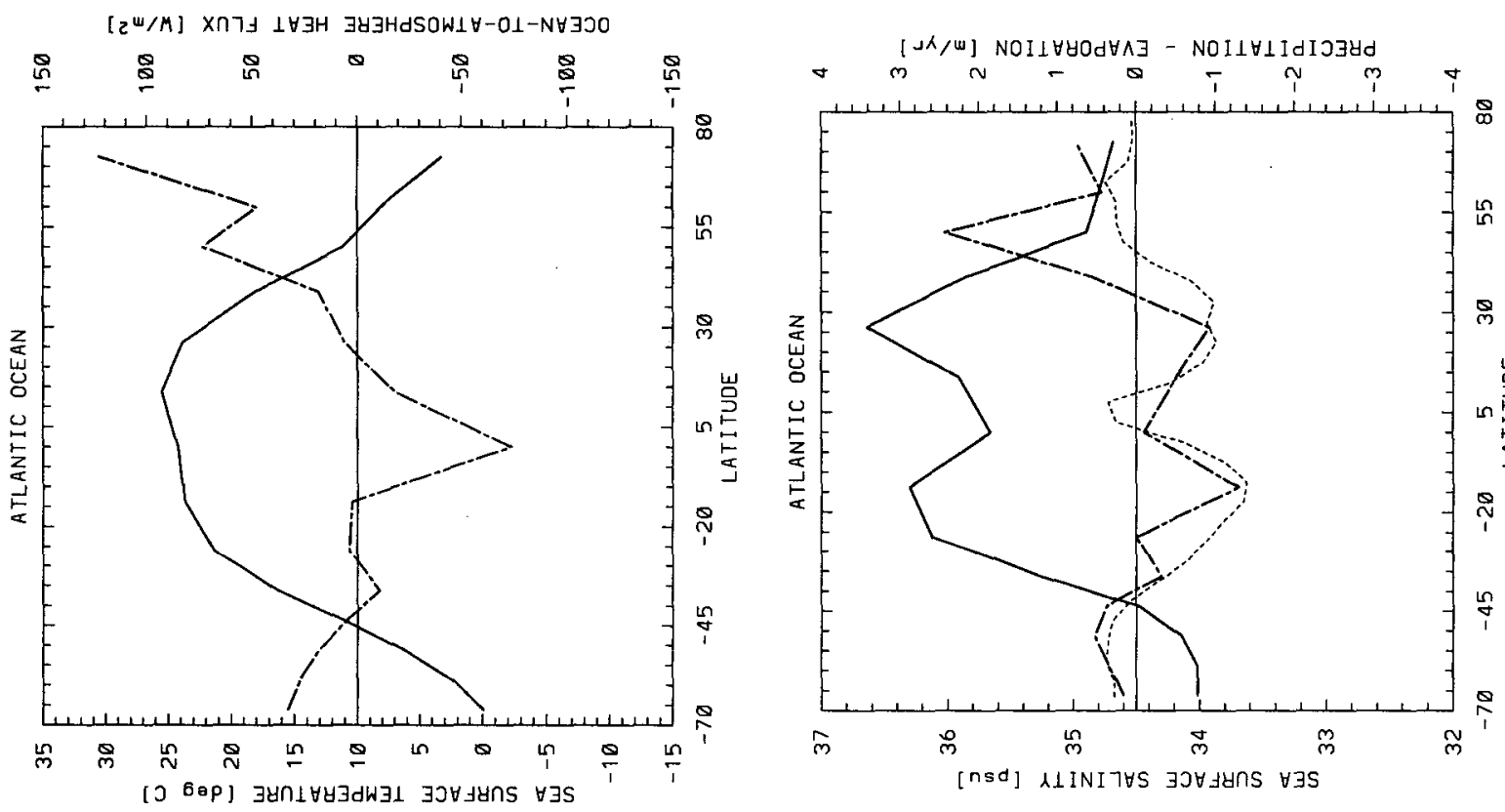

$[2 \Psi / M]$ Xการ $1 \forall \exists H \quad 383 H d S O W I \forall-0 \perp-N \forall 330$
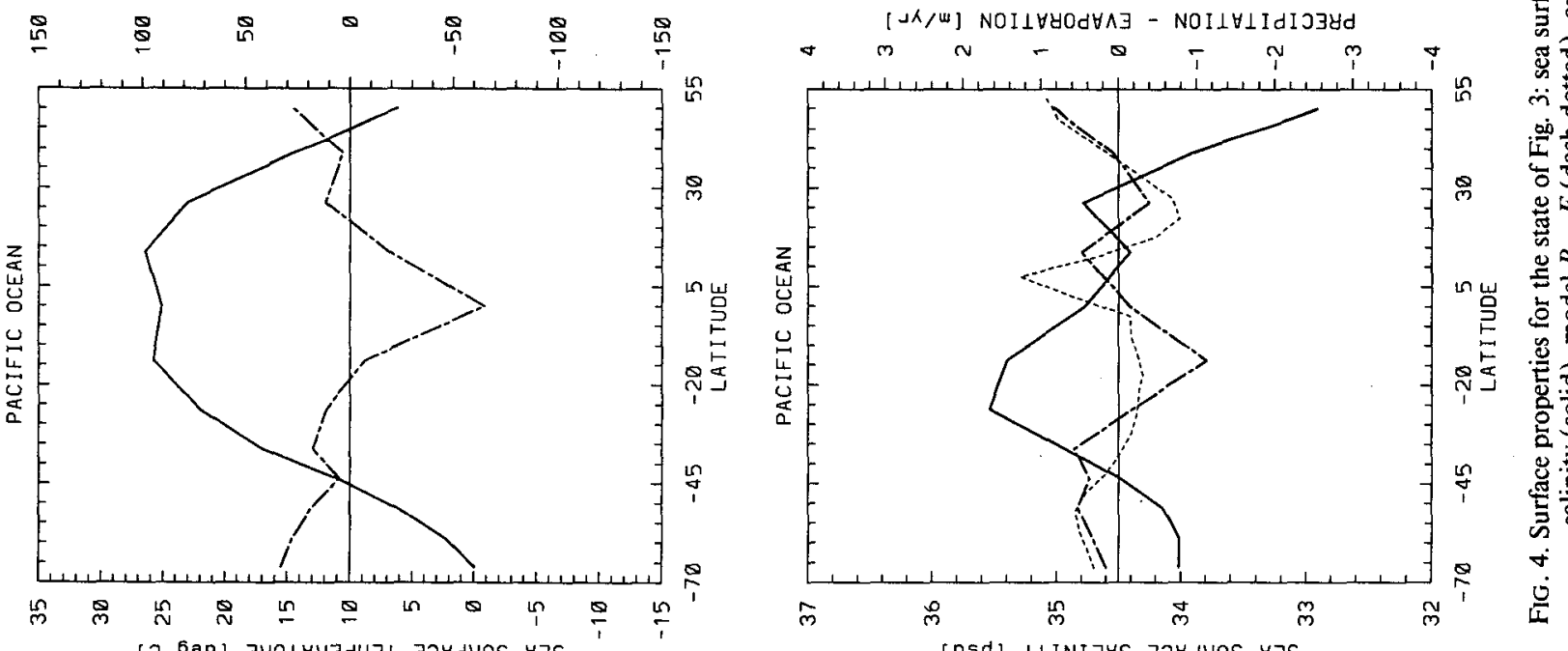

要 


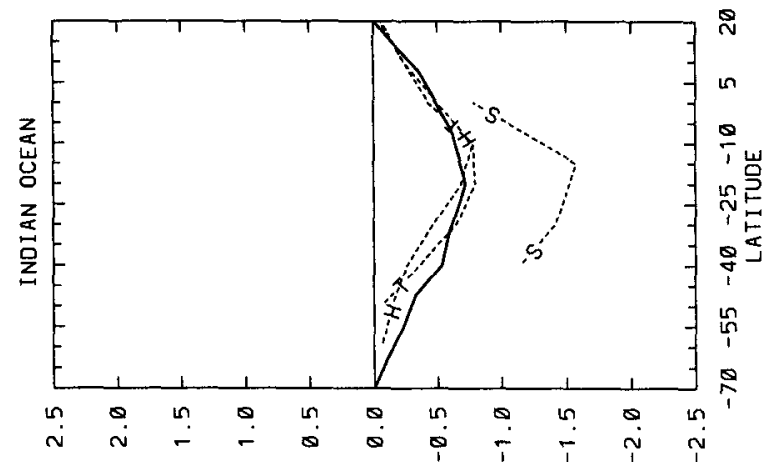

[Md] Xกา」 $1 \forall 3 H$ רHNOIOIYJW OINGJJO

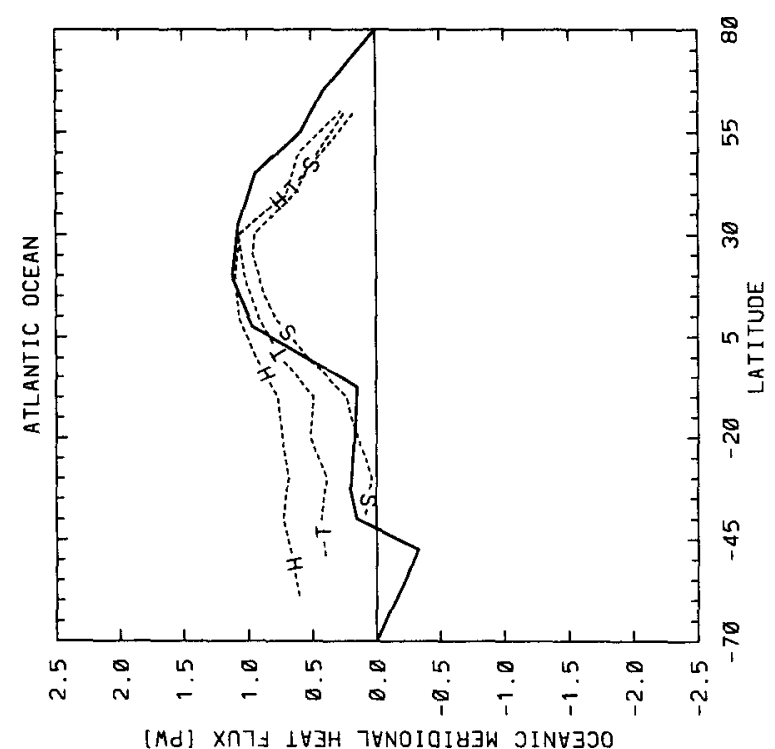

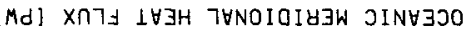

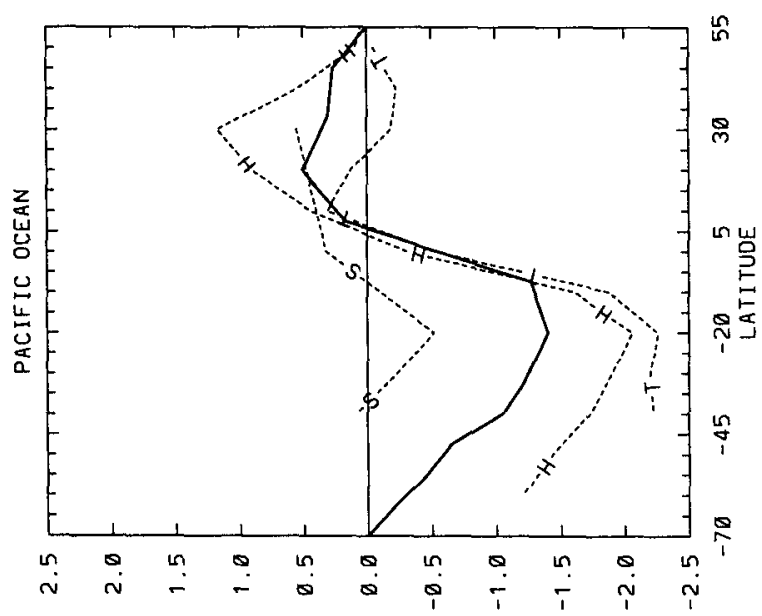

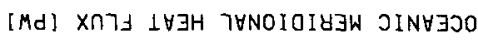

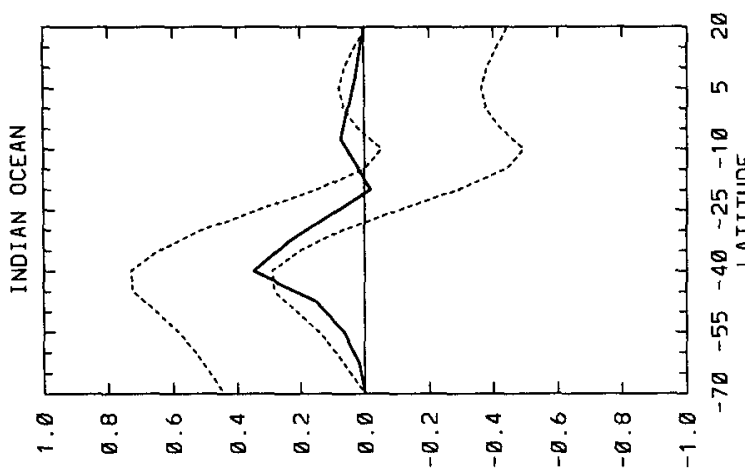

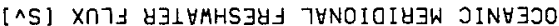

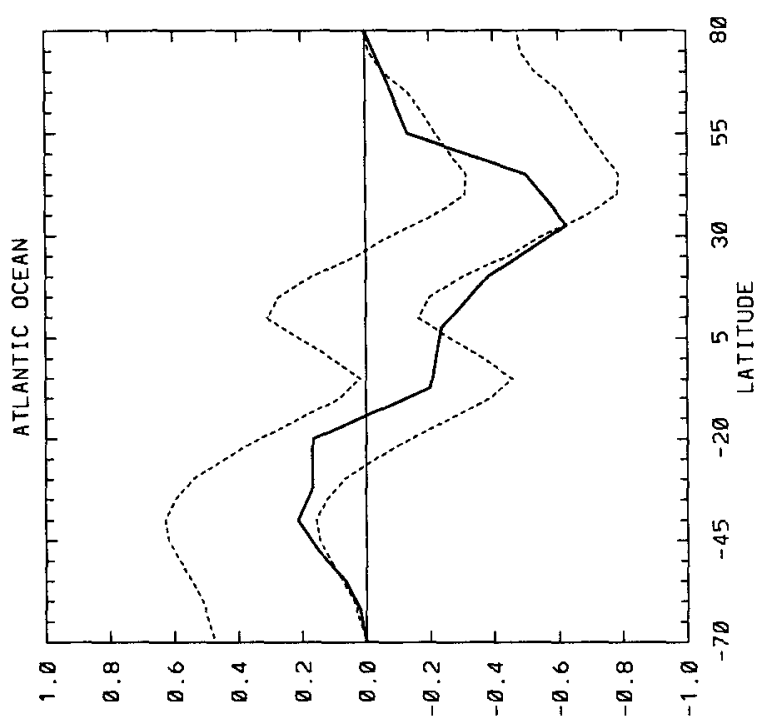

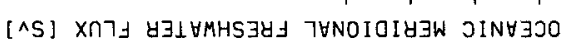

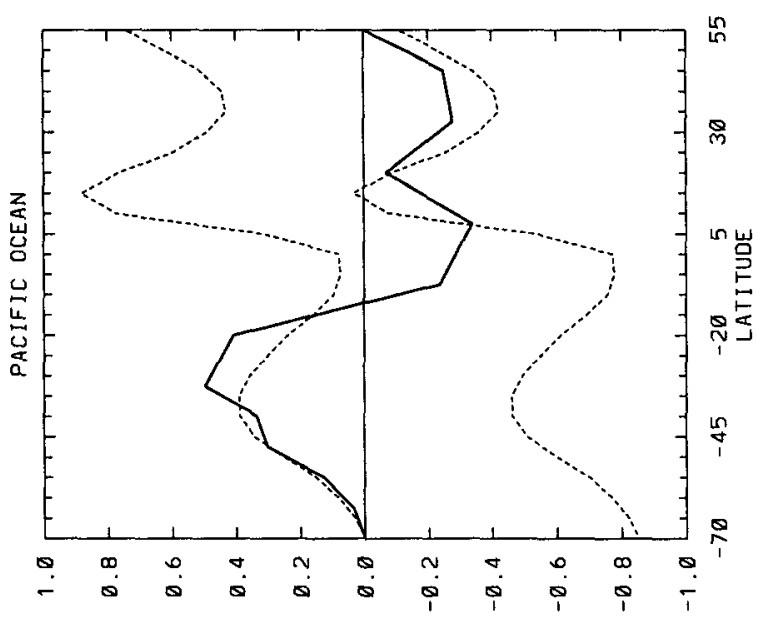

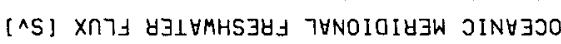

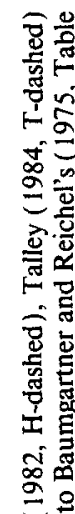

동

营

它

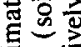

Ti

要要

$\circ \stackrel{0}{0}$

范 $\Xi$

象象

잉롱

屯

究

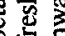

$\leqq \overline{\mathrm{G}}$

응

苋芯

画 ह

임등

言额

응.

के

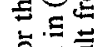

농

氖

造造

宫官

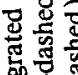

u

象兔

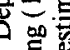


then continued in the coupled mode, with the parameter values in (23) and $E(\phi, i)-P(\phi, i)$ held constant (i.e., $\eta_{Z}=0$ ). The ocean subsequently went through a spinup period lasting about 500 years when large overturning rates were observed in all three basins. Initially, deep water was formed in both hemispheres of the Atlantic and Pacific. During that time, the net flux through the top of the atmosphere was about +1.5 $\mathrm{W} \mathrm{m} \mathrm{m}^{-2}$, indicating that energy was being lost to space. Five thousand years after the abrupt reset, the climate system has reached steady state, with an energy balance of $2 \times 10^{-4} \mathrm{~W} \mathrm{~m}^{-2}$. This final state is essentially identical with the previous steady state with the ocean being again in the conveyor-belt mode.

Figure 4 gives the surface properties in the three ocean basins. Sea surface temperatures (SST, Fig. 4a, solid) are close to those of Levitus (1982), and the ocean-to-atmosphere heat fluxes (Fig. 4a, dash-dotted) take reasonable values in all basins. Figure $4 b$ shows the sea surface salinity (SSS, solid) and $P-E$ (dashdotted); the latter compares favorably with the observations (dashed) of Baumgartner and Reichel (1975). Meridional heat and freshwater transports along with several observational estimates are given in Figs. 5a and $5 b$, respectively. The model reproduces the steep gradients of the Pacific heat flux as well as the correct maximum value of about $1 \mathrm{PW}\left(1 \mathrm{PW}=10^{15} \mathrm{~W}\right)$ and location of the northward Atlantic heat flux; also, in the Indian Ocean the meridional heat flux follows closely the estimates. The freshwater fluxes are compared with two estimates derived from the data of Baumgartner and Reichel. When $E-P$ is integrated southward starting from the northern end of the basin, assuming no horizontal flux there, the model fluxes deviate progressively toward the south. On the other hand, if the data is integrated starting from the southern end, the model fluxes differ increasingly toward the north. Our model fluxes are bracketed between these two extremes. Possible explanations for the discrepancies between model and observational estimates of the fluxes are explored in WS2.

The global overturning is given in Fig. 6a showing the general two-cell structure, which now also includes the surface Ekman cells around the equator and in the Southern Ocean. The global meridional heat flux (Fig. $6 \mathrm{~b}$ ) in the ocean fits surprisingly well those observations that are based on energy balance considerations at the ocean's surface (e.g., Hastenrath 1982). However, it differs from Carissimo et al. (1985), who obtain the ocean transport as a residual from satellite and atmospheric estimates.

The surface air temperature and the temperature contrast between ocean and atmosphere (Fig. 7a) clearly show the warm Atlantic SST and the relatively cooler Pacific SST as a consequence of the different directions of the meridional heat fluxes. In the coupled model, the SST is now a variable that is free to evolve, because the restoring boundary condition on temperature is no longer used. The meridional heat fluxes in the climate model are split up in Fig. $7 \mathrm{~b}$ showing the oceanic, latent, sensible plus potential, and total atmospheric and total global fluxes. The sensible heat flux is tuned by (25) to give a total meridional heat flux consistent with the flux divergence at the top of the atmosphere. The global water budget $E-P$ is given in Fig. 7c and compared to Baumgartner and Reichel (1975). Apart from the heavy precipitation in the equatorial regions, agreement is good. However, larger deviations in the individual $E$ and $P$ fields are found. This problem is resolved by using the more realistic
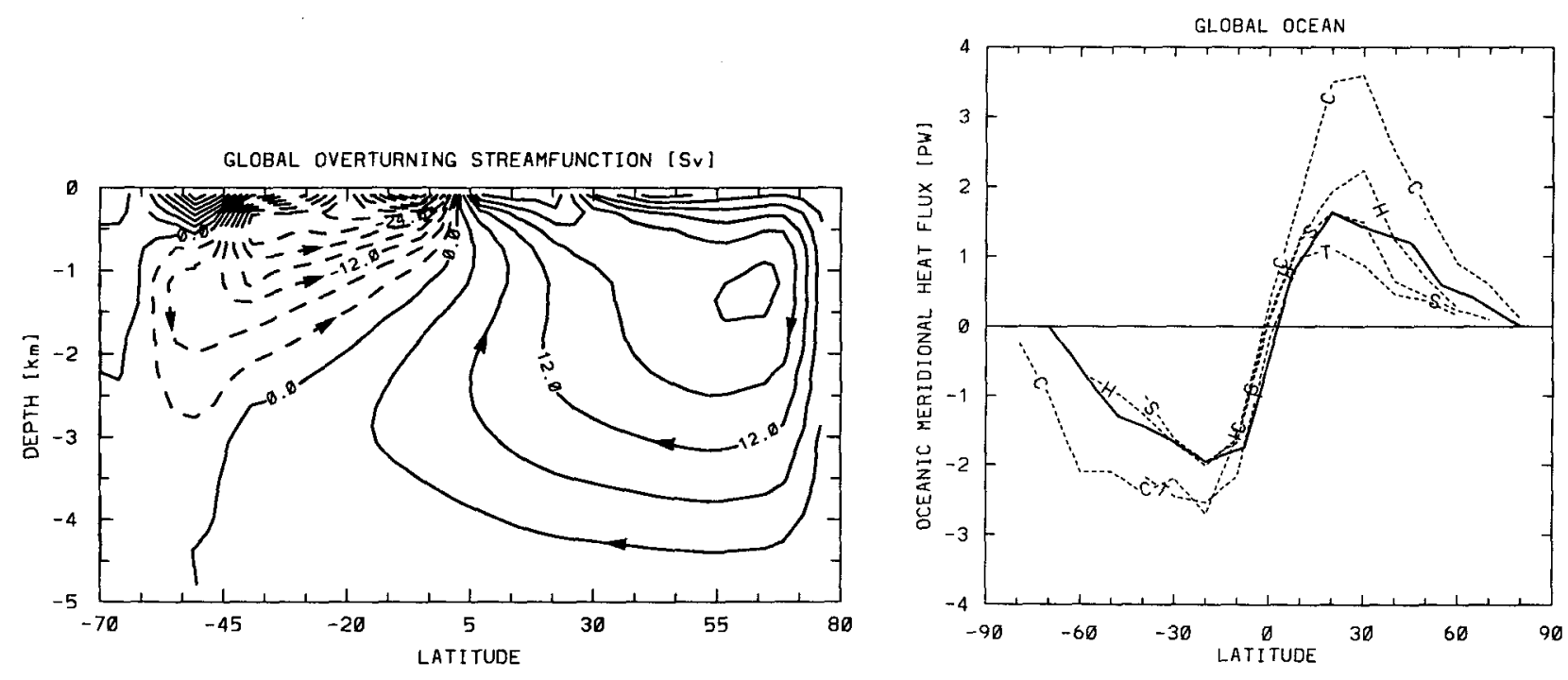

FIG. 6. Global meridional overturning (a: left) and heat flux (b: right, solid) for the state of Fig. 3 compared to observations by Hastenrath (1982, H-dashed), Talley (1984, T-dashed), Hsiung (1985, S-dashed), and Carissimo et al. (1985, C-dashed). 

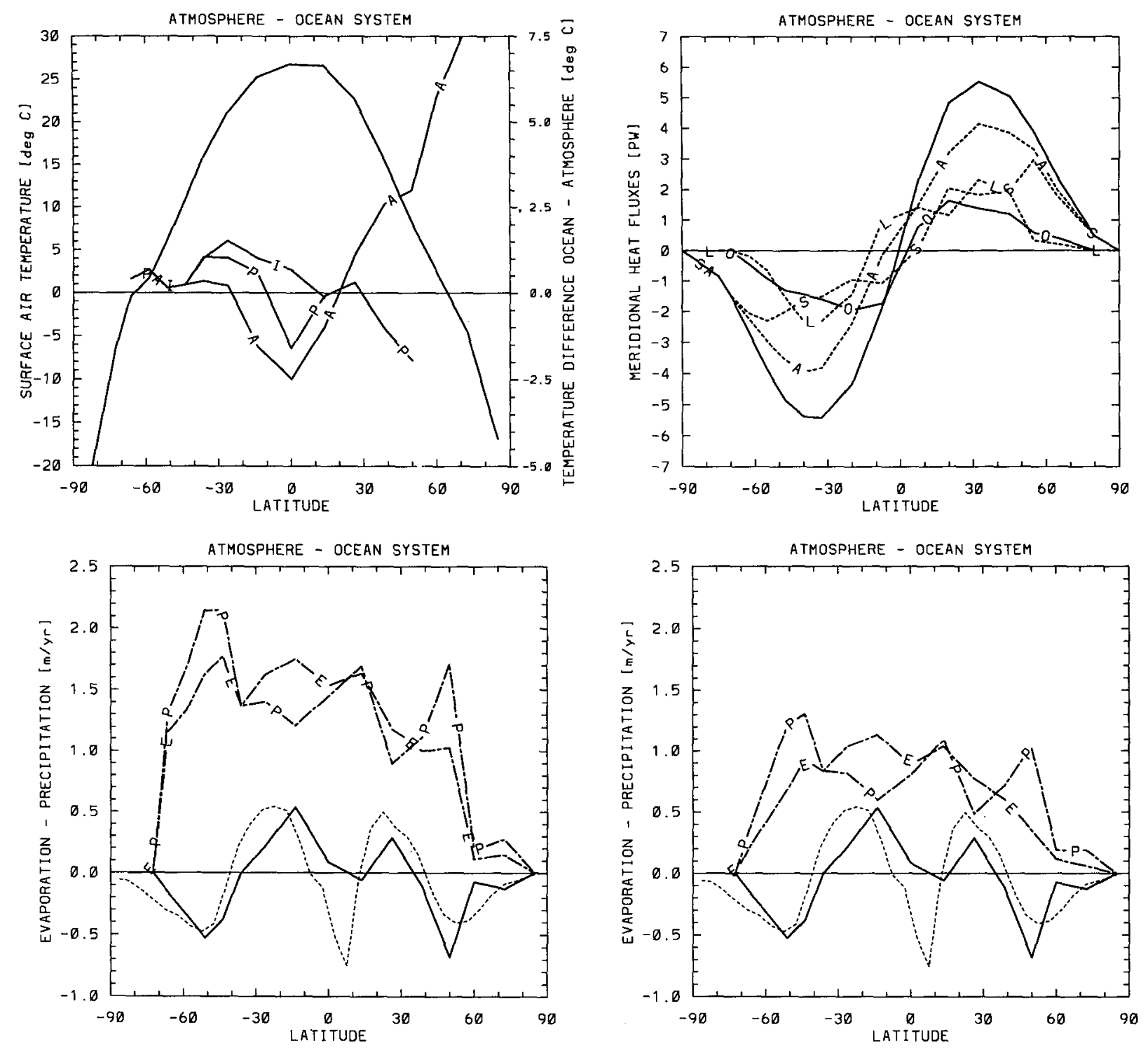

FIG. 7. Properties in the atmosphere for the state of Fig. 3: surface air temperature (solid) and the temperature contrast SST- $T_{A}$ in the three basins are shown in (a: top left). In (b: top right) the global meridional heat flux (solid) is broken up into the total atmospheric (Adashed), sensible plus potential (S-dashed), latent (L-dashed), and oceanic (O-solid) component. Global evaporation (E-dash-dotted) and precipitation ( $\mathbf{P}$-dash-dotted) in meters per year for two different parameterizations of the downwelling longwave radiation in the atmosphere are compared: $e_{A}=e_{O}=1$ in (c: bottom left), and $e_{O}=0.96, e_{A} \neq 1$ in (d, bottom right). Both cases have identical global E-P (solid), which is in fair agreement with the data of Baumgartner and Reichel (1975, dashed).

parameterization for the longwave radiation in (17) with $e_{O}$ and $e_{A} \neq 1$ (Fig. 7d). While the surface water budget is not altered, $P$ is now reduced to more realistic values not exceeding $1.5 \mathrm{~m} \mathrm{yr}^{-1}$, and $E$ follows observational estimates. This alters the models' sensitivity to freshwater flux anomalies (see section $4 b$ ).

In Fig. 8a, the objectively determined atmospheric eddy diffusivity is shown and compared to other studies. Agreement with the values of Harvey (1988) is found with somewhat stronger latitude dependence. For comparison, also the diffusivities of Sellers (1969) are given. If wind stress is absent, $K_{A}$ increases to 30 $\times 10^{6} \mathrm{~m}^{2} \mathrm{~s}^{-1}$ just north of the equator. The various emissivities are displayed in Fig. 8b. The planetary emissivity is typically around 0.6 with larger values in the high latitudes. For the emissivity of upwelling longwave radiation at the ocean surface, we assume a constant value of 0.96 , while the emissivity for the downwelling atmospheric longwave radiation over each ocean basin is determined by (27).

\section{b. Climate drift and intermittent convection}

A particularly disturbing property of the present generation of three-dimensional coupled models is the 


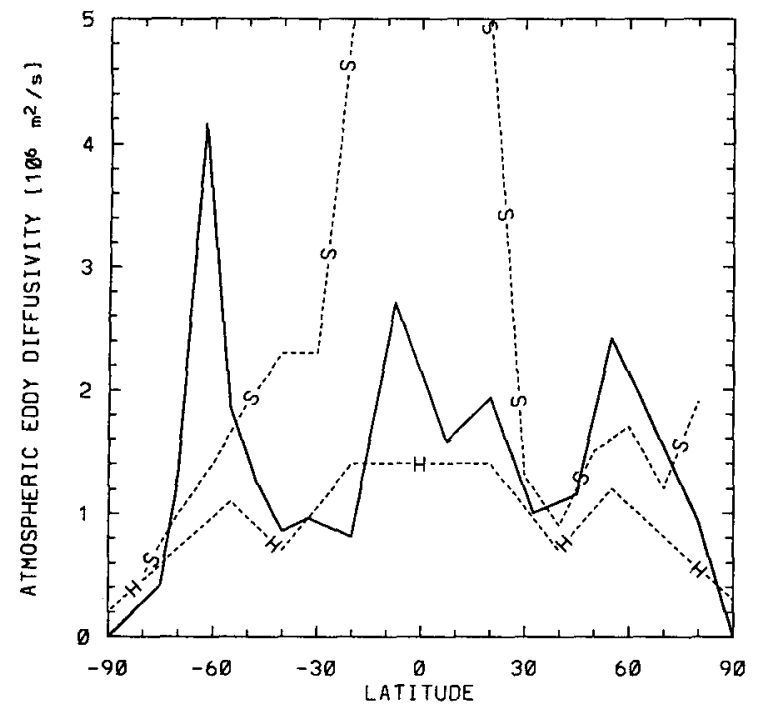

FIG. 8a. Atmospheric eddy diffusivity $K_{A}$ in $10^{6} \mathrm{~m}^{2} \mathrm{~s}^{-1}$ objectively determined by observations and the steady state of the ocean of Figs. 3-7 (solid). The values used by Harvey (1988, H-dashed) and Sellers (1969, S-dashed) are given for comparison.

occurrence of climate drift resulting in steady-state climates that are systematically biased from the observed climate. While both atmosphere and ocean components produce reasonable steady states when integrated individually, the coupled model often evolves away from the original state. Manabe and Stouffer (1988) report a climate drift showing systematic positive deviations of SSS in the North Pacific until this region becomes saltier than the Atlantic. To counterbalance this tendency, a flux correction is introduced by modifying $E-P$ with values that, in particular locations, are very large $\left(>5 \mathrm{~m} \mathrm{yr}^{-1}\right)$. The rationale is that the model is still capable of accurately predicting changes to this state provided these are determined from differences of a control run (with the model bias) and a perturbation run (with the same model bias).

On the other hand, less complex climate models, such as pure energy balance models, are unlikely to exhibit climate drift because of their basically diffusive character. With the present model we are in an intermediate realm where the dynamics of the ocean can interact with a simple atmosphere. Climate drift away from a steady state has not been observed in the zonally averaged model of the Pacific-Atlantic basin system (SW1; SW2), although in rare cases intermittent convection has occurred. However, the present three-basin model has shown climate drift with dramatic consequences for the global thermohaline circulation. This occurs only for certain values of the model parameters. This qualitative difference is likely due to the different surface forcing profiles (analytical in SW1, SW2) and the larger horizontal diffusivities $\left(K_{H}=10^{4} \mathrm{~m}^{2} \mathrm{~s}^{-1}\right)$

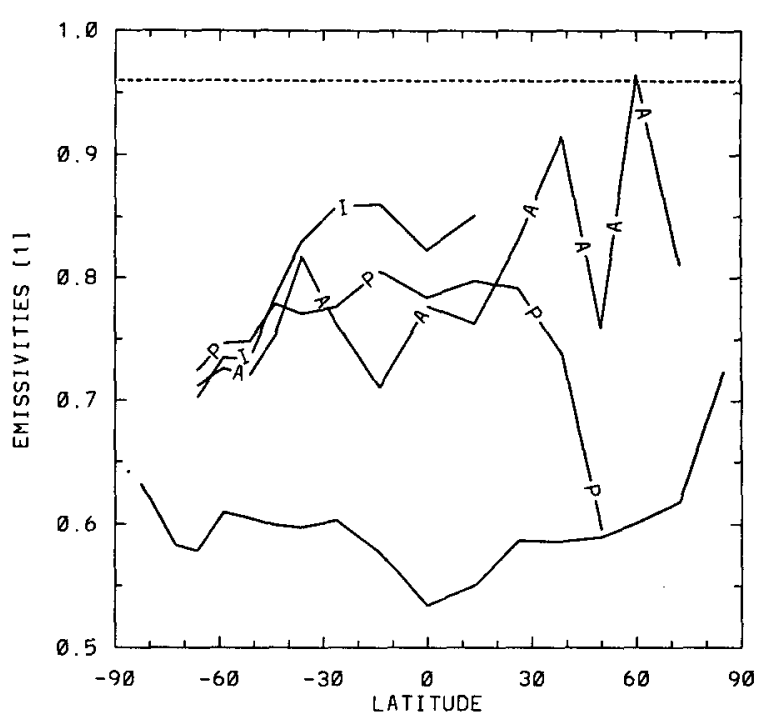

FIG. 8b. Emissivities for upwelling longwave radiation: planetary emissivity (solid) at the top of the atmosphere, constant emissivity at the ocean surface (dashed) and the objectively determined emissivities for downwelling longwave radiation at the ocean surface over Pacific (P-solid), Atlantic (A-solid), and Indian (I-solid) oceans.

used in the earlier studies. Consequently, the steady states of the model were generally less sensitive to perturbations (see also section $4 \mathrm{~b}$ ). The closer a steady state is to a transition point between two stable equilibria (e.g., SW2), the weaker its stability is to perturbations, and the more likely it is that intermittent convection will cause an irreversible climate drift.

Three experiments, A1, A2, and B, are performed with the ocean model spun up from rest under restoring boundary conditions (6) without wind stress for 4000 years and then coupled to the atmosphere for 2000 years with $\eta_{Z}=0$. We select $K_{H}=10^{3} \mathrm{~m}^{2} \mathrm{~s}^{-1}, K_{V}$ $=0.5 \times 10^{-4} \mathrm{~m}^{2} \mathrm{~s}^{-1}$, and, for the restoring temperature in the North Pacific, $T^{*}$ (Pacific, $50^{\circ} \mathrm{N}$ ) $=6.1^{\circ} \mathrm{C}$ for $\mathrm{A} 1$ and $\mathrm{A} 2$, and $6.3^{\circ} \mathrm{C}$ for $\mathrm{B}$. The cooler restoring temperature produces intermittent convection in the North Pacific, reaching to $100-\mathrm{m}$ depth about every tenth time step in the runs A1 and A2. Decreasing the buoyancy flux in B by slightly increasing $T^{*}\left(\right.$ Pacific, $50^{\circ} \mathrm{N}$ ) removes this intermittent convection. Thus, under restoring boundary conditions, the surface balances of heat and salt in experiment $B$ decrease monotonically toward zero, while for A1 and A2 the state is only statistically steady. This is shown in Fig. 9a, where the time series of SSS at the highest northern latitude for each basin (P-, A-, I-solid) and of $F^{\mathrm{OA}}$ (solid) integrated over all basins are given. In Al (top) the instantaneous values of $F^{\mathrm{OA}}$ and $Q_{S}^{*}$ at 4000 years are diagnosed and used to initialize the coupled run, whereas for A2 (middle) we took the time average of these fluxes over the preceding 500 years. In B (bottom) no intermittent 
convection was present, and the instantaneous surface fluxes were diagnosed at the time of coupling.

In experiment Al the Pacific SSS starts increasing immediately after coupling, and the Pacific has become saltier than the Atlantic after about 1000 years. The evolution of the maximum (solid) and minimum (dashed) streamfunction in the Pacific and Atlantic is given in Fig. 9b. During these experiments, the Indian Ocean overturning never changes substantially and is thus not shown here. Upwelling in the Pacific (along with downwelling in the Southern Ocean) gradually diminishes, while deep water starts to form in the North Pacific. The Atlantic thermohaline circulation undergoes transient fluctuations lasting about 400 years but remains essentially in the same state. The climate drift in this model is consistent with the drift observed in the three-dimensional model of Manabe and Stouffer (1988). Our final steady state shows deep-water formation in both the North Pacific and North Atlantic and corresponds to the "Northern Sinking" state of Marotzke and Willebrand (1991).

The same experiment is repeated in A2 except that we now use time-averaged fluxes to diagnose the atmospheric parameters at the time of coupling. Although this initially has a stabilizing effect, after about 1300 years the transition begins, and the Pacific thermohaline circulation reverses. The evolution is somewhat different from A $1: F^{\mathrm{OA}}$ decreases about 200 years previous to the increase of SSS in the North Pacific and the beginning of deep-water formation. It appears that the sinking in the Pacific section of the Southern Ocean diminishes first with a subsequent reduction of heat release to the atmosphere. This reduces the supply of dense water flowing north in the deep Pacific but also extends the residence time of the surface waters in equatorial regions. Note that because $\eta_{Z}=0$ the net surface freshwater flux remains unchanged in the coupled mode, and the surface waters become more saline in equatorial regions. It takes the northward surface flow in the Pacific (north of $5^{\circ} \mathrm{N}$ ) about 150 years to carry this positive salinity anomaly to $50^{\circ} \mathrm{N}$ where deep-water formation is subsequently triggered. This explains the lag observed in Fig. 9b.

Long-term climate studies are thus not possible under such circumstances. For the present experiments we chose $\eta_{Z}=0$ so as not to induce instabilities by interbasin exchange of freshwater through the atmosphere. The effects seen here must thus be linked to local conditions in the ocean. If intermittent convection is present, the surface fields in these areas cannot converge to the accuracy required for a stable steady state in the model. This can modify the stability of a given circulation. It must be mentioned in this context that similar mode transitions were observed even without intermittent convection, when the spinup time was not long enough for the salinity fields to converge.

In experiment $B$ intermittent convection is removed from the outset. This is achieved by slightly modifying the surface forcing in the northernmost box of the $\mathrm{Pa}$ cific basin (increase of the restoring temperature by $0.2^{\circ} \mathrm{C}$ ). The model now converges monotonically to a steady state as is seen in the decrease of the surfaceintegrated ocean-to-atmosphere heat flux in Fig. 9a (bottom). At 4000 years the instantaneous fluxes are diagnosed, and integration continues in the coupled mode. No transitions are observed and the state is steady. This is further confirmed by a subsequent integration for another 12000 years. Two different procedures can thus prevent immediate climate drift in the present model. Time averaging before diagnosing the surface fluxes stabilizes the mode but is unable to avoid an eventual transition. With the removal of intermittent convection, however, the state has become stable to finite salinity perturbations. This was checked by adding positive salinity anomalies to the North $\mathrm{Pa}$ cific, the region that is most sensitive to such perturbations.

\section{Deglaciation experiments}

\section{a. Various steady states of the coupled model}

Box models (Marotzke 1990) suggest that there are many possible steady states of the global thermohaline circulation, but we have found only four different equilibrium states in our model. They can be characterized according to their thermohaline climate in the different ocean basins. The circulation in the Indian Ocean was never observed to change direction for the present runs. This is due to the fact that the basin extends only to $20^{\circ} \mathrm{N}$, where the temperature effect is always dominating, and thus upwelling prevails. Figure 10 shows three equilibrium states that can exist under identical boundary conditions. The conveyor-belt circulation always results when spinning up the ocean model under present-day surface forcing (Fig. 10a). The state does not exhibit further transitions, neither under mixed boundary conditions nor in the coupled mode, provided no intermittent convection is present. Figure $10 \mathrm{~b}$ shows a state in which the Atlantic circulation has reversed and deep water is produced only in the Southern Ocean (termed "Southern Sinking" by Marotzke and Willebrand 1991). This state was also reported in SW1 and formed, together with the conveyor-belt circulation, a hysteresis behavior as a function of the atmospheric Atlantic-to-Pacific freshwater transport (SW2). It will be shown below that the reversed conveyor belt (Fig. 10c) can also be realized in the coupled model as an equilibrium state under identical boundary conditions. The fourth state (not shown) was observed only when intermittent convection in the Pacific caused a climate drift: deep water is formed in both North Pacific and North Atlantic. 

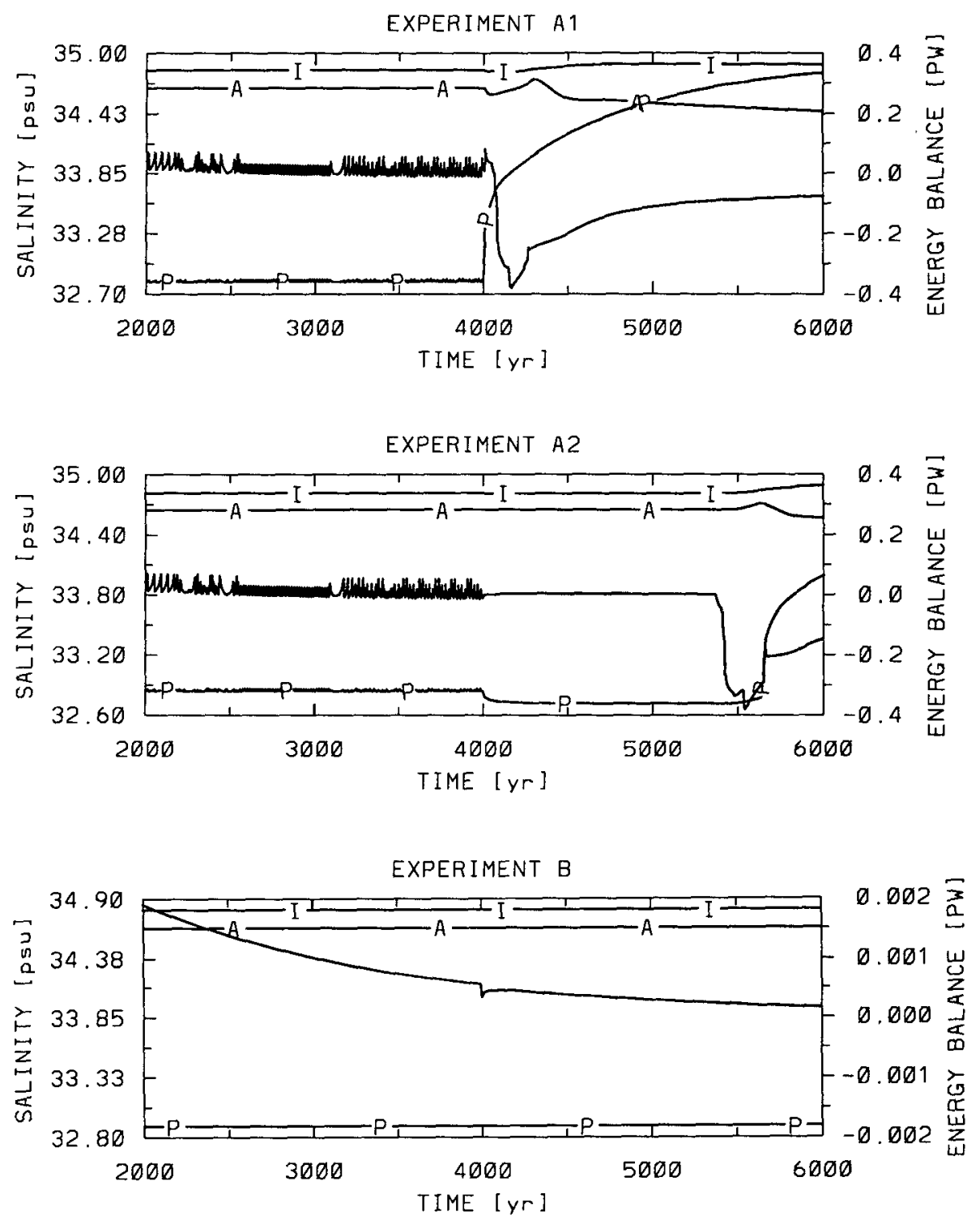

FIG. 9a. Evolution of sea surface salinity in the northernmost grid boxes of the Pacific (Psolid), the Atlantic (A-solid), and the Indian (I-solid) oceans and the globally integrated heat flux $F^{\mathrm{OA}}$ in petawatts ( solid). Restoring boundary conditions are applied in the ocean-only mode until 4000 years at which time the surface fluxes are diagnosed instantaneously (for experiment $A 1$ and $B$ ) or averaged over the last 500 years (for experiment A2), and integration continues in the coupled mode. In experiments A1 (top) and A2 (middle), intermittent convection is present in the North Pacific as evident from $F^{\mathrm{OA}}$. This causes upon coupling a transition to a state where deep water is forming in both North Pacific and North Atlantic. In experiment B (bottom), intermittent convection is removed by slightly increasing the restoring temperature at the location of intermittent convection, and the state remains steady in the coupled mode.

These four equilibrium states are consistent with the four states presented by Marotzke and Willebrand (1991). They used the three-dimensional Bryan-Cox OGCM in a highly symmetric geometry with two identical basins that are connected by a circumpolar channel. Their surface forcing was identical for both basins and symmetric about the equator, and hence the present-day conveyor belt was not a preferred state of the model as is the case here. The important point is that the zonally averaged model again produces results that are in agreement with a more complex three-dimensional OGCM. 

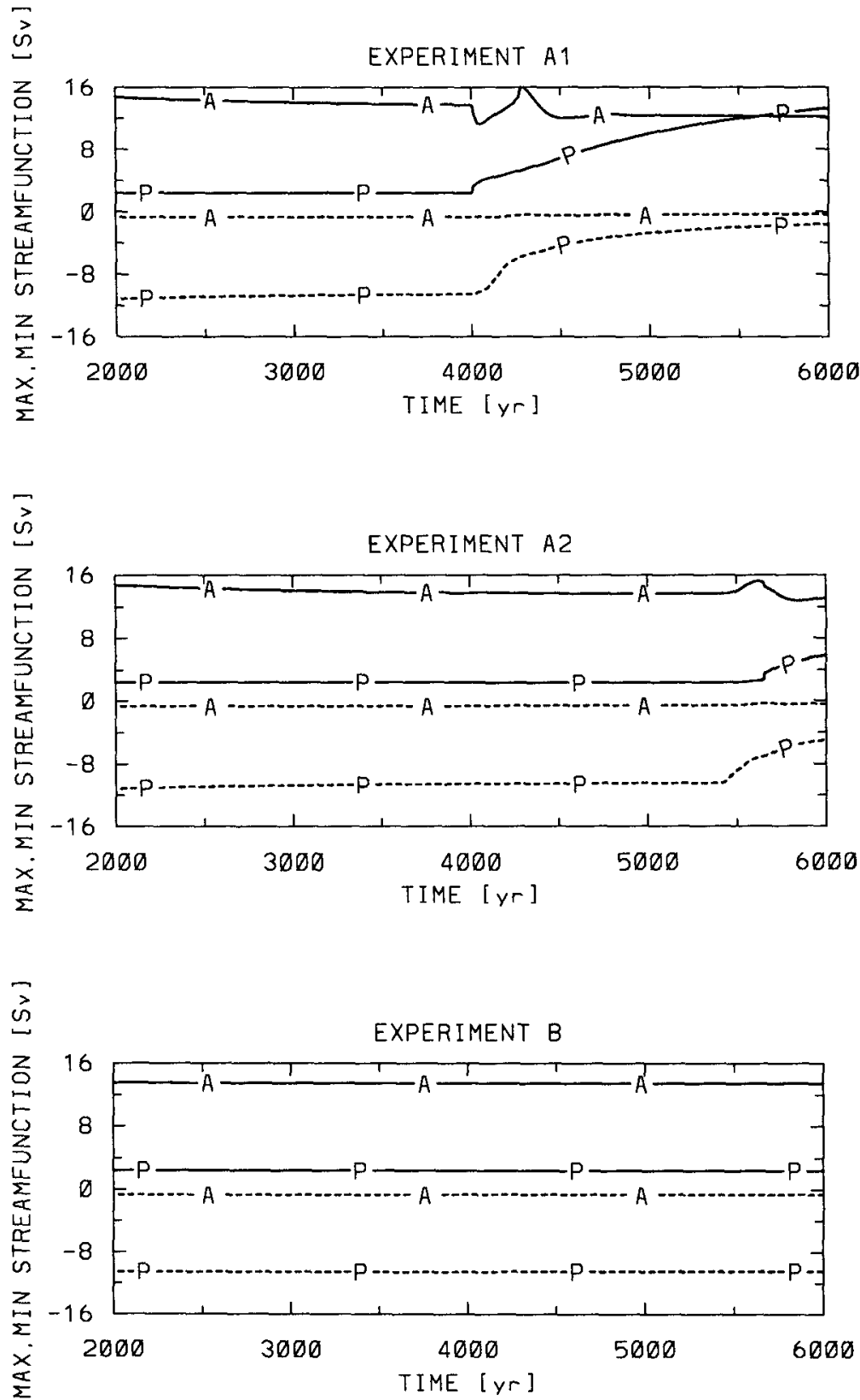

FIG. 9b. As in Fig. 9a but for the maximum (solid) and minimum (dashed) streamfunction in the Pacific and Atlantic; no significant changes occur in the Indian Ocean.

The first two of the three states in Fig. 10 have most likely been operating in our climate system at different times. Over the past several thousand years, the World Ocean has not exhibited fundamental changes such as the global-scale reversals of the thermohaline circulation shown here. Present-day observations (Gordon 1986) and three-dimensional model results (MaierReimer and Mikolajewicz 1989) indicate that the ocean is in the conveyor-belt mode. There is evidence from geochemical analyses of deep-sea cores that during the glacial maximum (18000 BP), vertical mixing and deep-water formation in the North Atlantic were reduced (Boyle and Keigwin 1987). Duplessy et al. (1988) reconstruct a latitude-depth section of a carbon isotope ratio and find that southern Ocean deep water was penetrating farther north than today in the Atlantic during the glacial. Additionally, intermediate water formation in the North Pacific was enhanced. The state 
PACIFIC STREAMFUNCTION [SV]

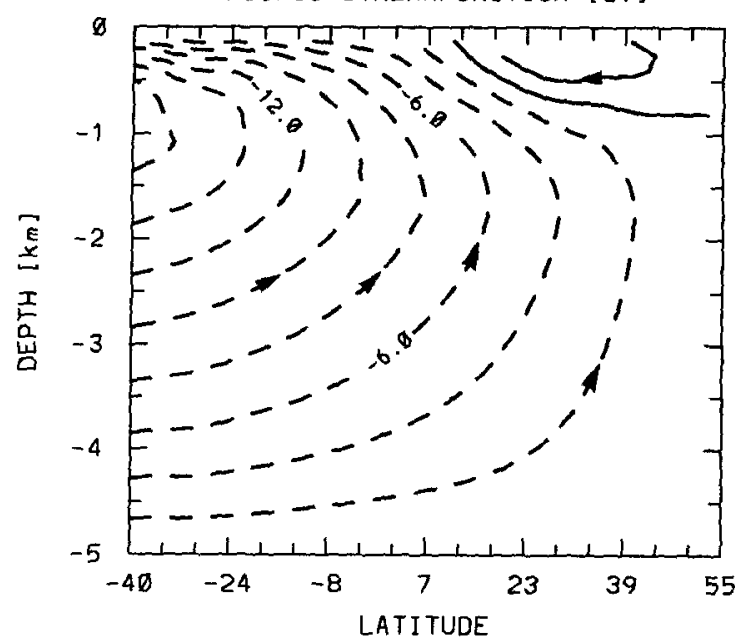

PACIFIC STREAMFUNCTION [Sv]

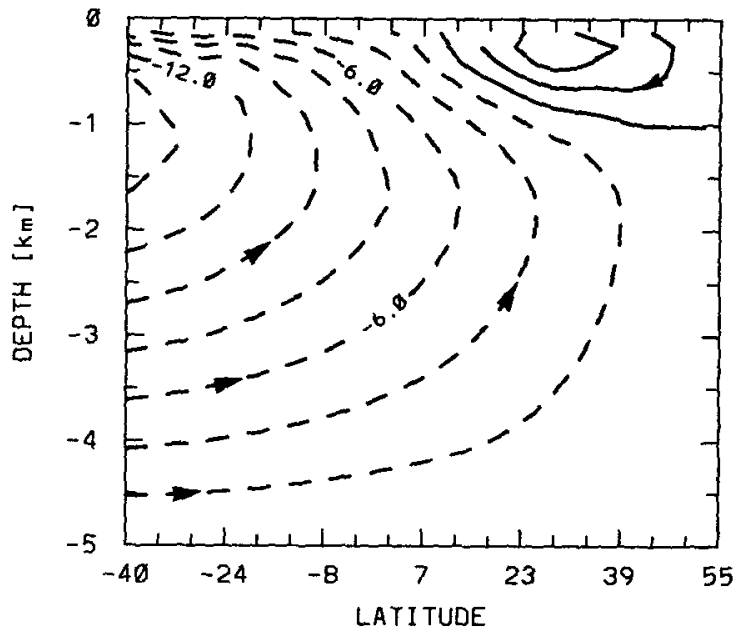

PACIFIC STREAMFUNCTION [SV]

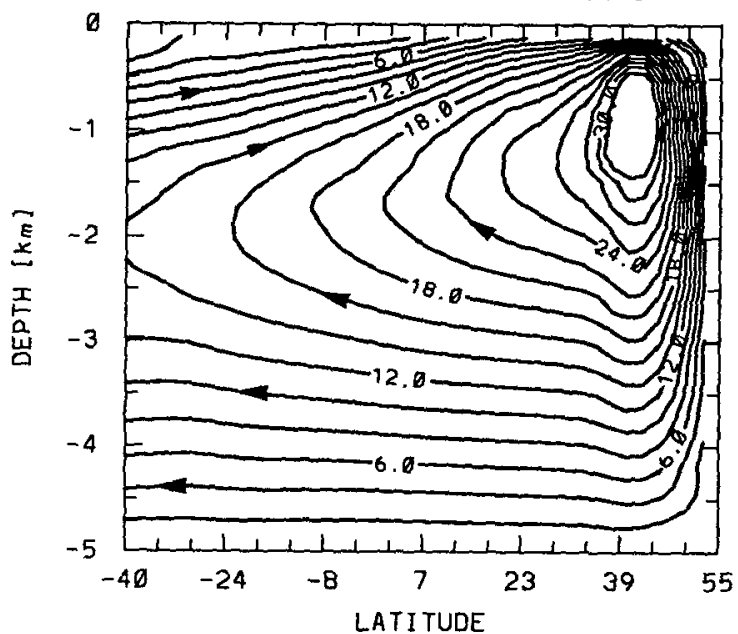

ATLANTIC STREAMFUNCTION [Sv]

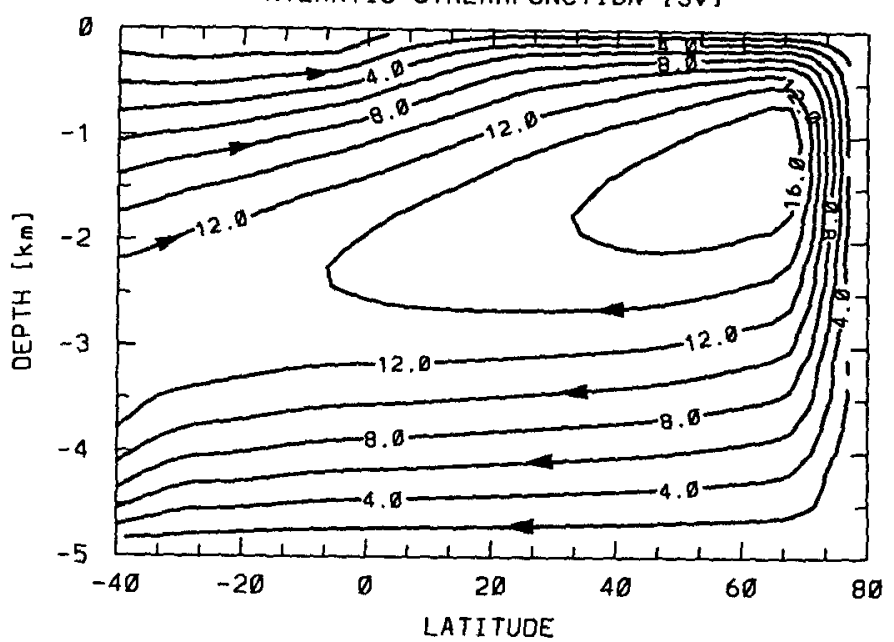

ATLANTIC STREAMFUNCTION [SV]

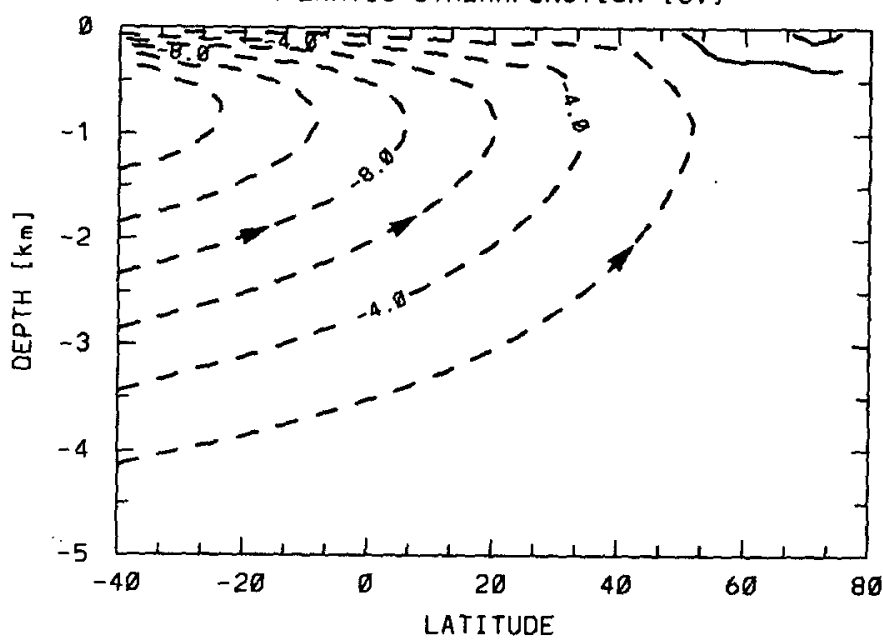

ATLANTIC STREAMFUNCTION [SV]

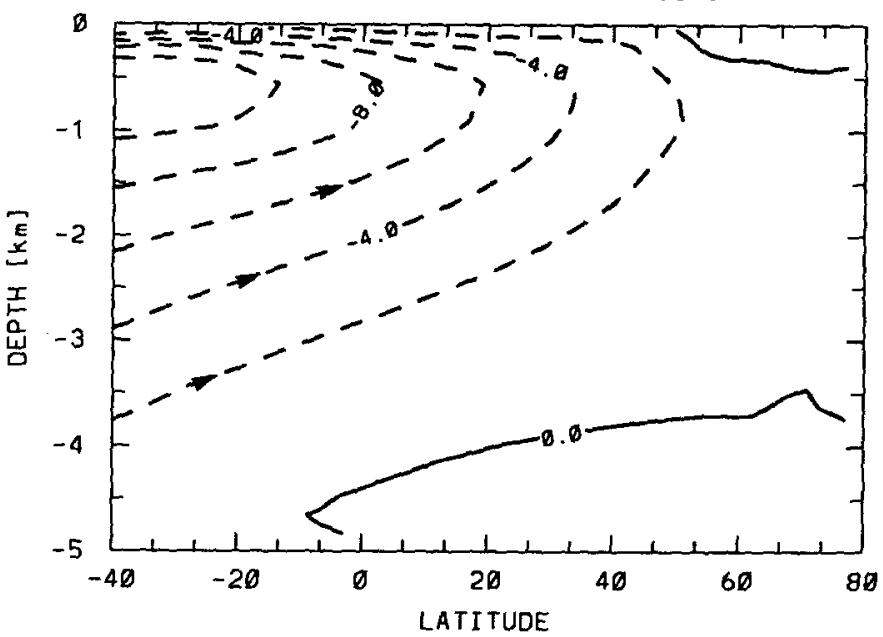

FIG. 10. Three states of the Pacific and Atlantic thermohaline circulation after 1000 years of anomalous runoff into the North Atlantic: (a: top row) is the slightly perturbed conveyor belt. In (b: middle row) the Atlantic circulation has reversed with somewhat increased intermediate water formation in the North Pacific (termed Southern Sinking), and (c: bottom row) shows the reversed conveyor belt. The Indian Ocean circulation does not change significantly and remains as in Fig. 2a. 
of Fig. $10 \mathrm{~b}$ is consistent with a number of these interpretations. It is tempting to speculate about whether or not the World Ocean was operating in the third mode (Fig. 10c) at some time in the past. However, it is only through the analysis of paleoclimatic proxy records from regions influenced by the Pacific Ocean, that this question will be resolved.

A strong motivation to consider a coupled model is that under the full flux boundary conditions (20) the sea surface temperatures in all basins are free to evolve. Figure 11a shows the surface air temperature $T_{A}$ and the ocean-atmosphere temperature contrast $\left(\mathrm{SST}-T_{A}\right)$ for the conveyor-belt circulation in Fig. 10a. The North Atlantic Ocean is about $7^{\circ} \mathrm{C}$ warmer and the North Pacific is about $2^{\circ} \mathrm{C}$ cooler than the overlying atmosphere. Except for the Indian Ocean, the equatorial waters are cooler than the atmosphere. The comparison between the "Southern Sinking" state (Fig. 10b) and the conveyor belt is illustrated in Fig. $11 \mathrm{~b}$ by the temperature differences $T_{A}^{\text {[Southern Sinking] }}-T_{A}^{\text {[conveyor] }}$ and $\left(\mathrm{SST}-T_{A}\right)^{[\text {[Southern Sinking] }}-\left(\mathrm{SST}-T_{A}\right)^{\text {[conveyor] }}$. The Atlantic SST is about $4^{\circ} \mathrm{C}$ cooler in the "Southern Sinking" mode, resulting in a global temperature change in the atmosphere of maximum $2.6^{\circ} \mathrm{C}$ at $70^{\circ} \mathrm{N}$. In the Southern Hemisphere a warming is experienced. Changes to the SST in the Pacific and Indian oceans do not exceed $0.25^{\circ} \mathrm{C}$. The temperature differences between the reversed (Fig. 10c) and the present-day conveyor belt are displayed in Fig. $11 \mathrm{c}$. Now the Northern Hemisphere is cooling only north of $60^{\circ} \mathrm{N}$, reflecting the fact that the loss of heat supply in the Atlantic is compensated by the gain in the Pacific. The reversal of the thermohaline circulation in the Pacific is also

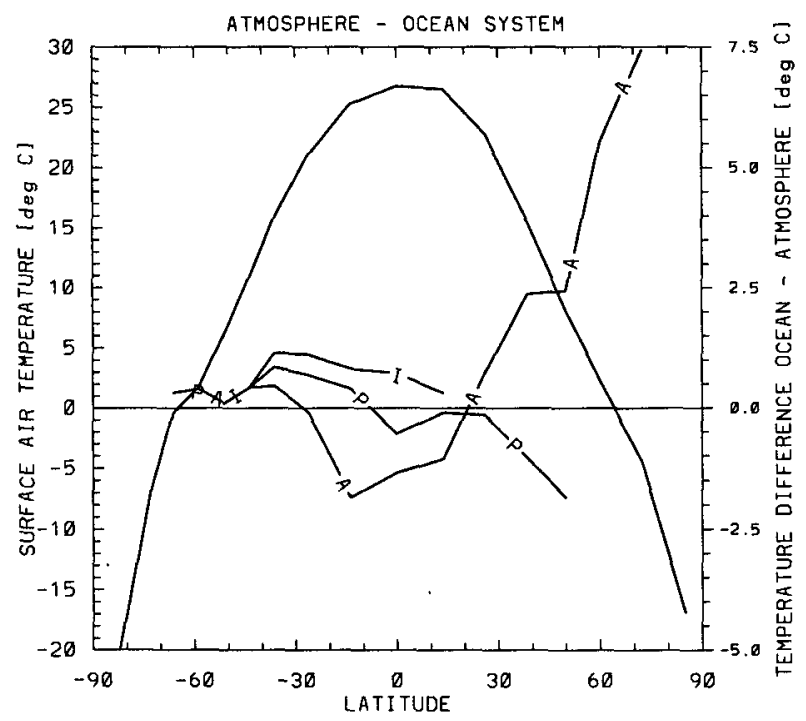

FIG. 11a. Surface air temperature (solid) and the temperature contrast between the ocean and the atmosphere in the three basins (A-, P-, and I-solid) for the conveyor belt in Fig. 10a. The model reproduces the warm North Atlantic and the cool North Pacific SST.

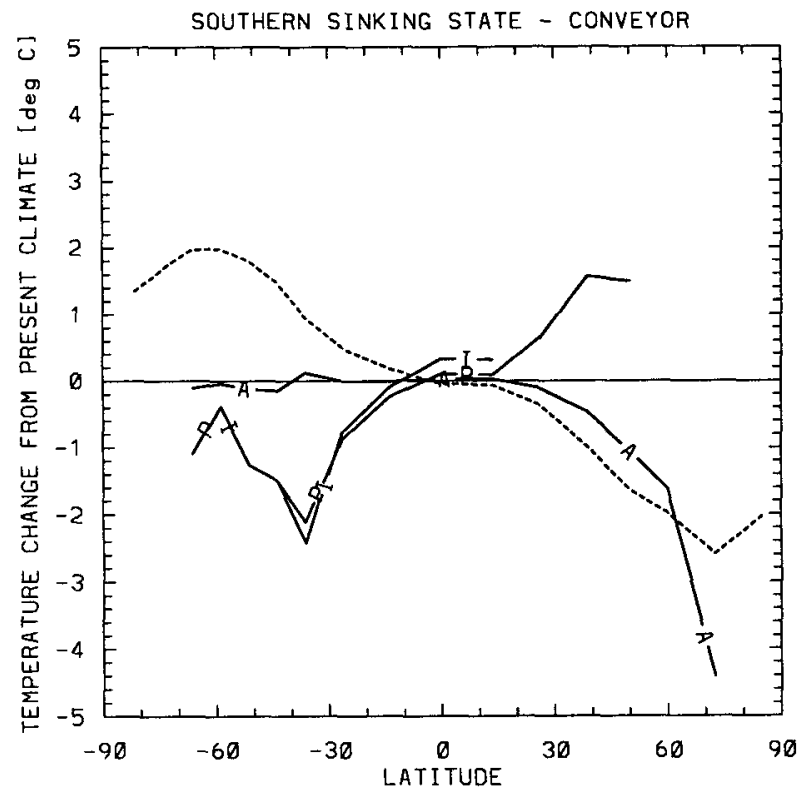

FIG. 1 lb. Temperature differences between the "Southern Sinking" state (Fig. 10b) and the conveyor belt (Fig. 10a): air temperature $T_{A}^{\text {[Southern Sinking] }} T_{A}^{\text {[conveyor] }}$ (dashed) and ocean-atmosphere temperature contrast $\left(\mathrm{SST}-T_{A}\right)^{\text {[Southern Sinking] }}-\left(\mathrm{SST}-T_{A}\right)^{\text {[conveyor }]}$ (solid) for the three basins. Note that the scale must be divided by 10 for the small differences in the Pacific and Indian oceans.

responsible for the general cooling in the Southern Hemisphere.

\section{b. Sensitivity to runoff into the Atlantic}

Denton and Hughes (1981) estimated that during the termination of the last ice age, about $30 \times 10^{6} \mathrm{~km}^{3}$

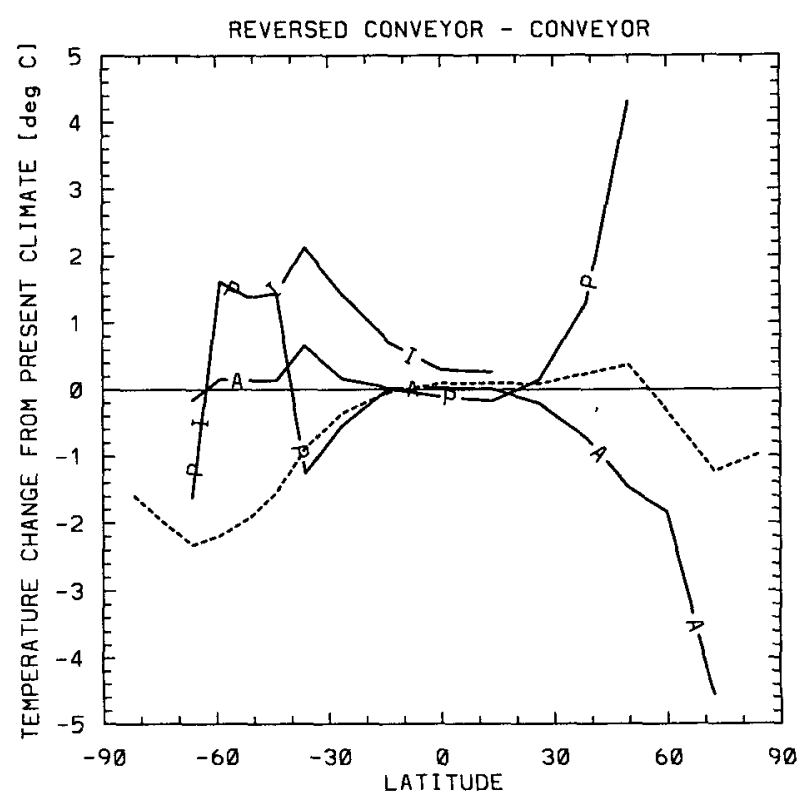

FIG. 11 c. As Fig. $11 \mathrm{~b}$ but for the reversed conveyor belt (Fig. 10c). 
ice melted in the Northern Hemisphere. A large portion of this excess water reached the Atlantic Ocean through runoff. It is thus a relevant experiment to study the sensitivity of the model's thermohaline circulation to such an anomalous freshwater flux. Maier-Reimer and Mikolajewicz (1989) examined the sensitivity of their OGCM to freshwater fluxes applied to the North Atlantic and found that deep-water formation could be switched off with an anomaly of only $0.01 \mathrm{~Sv}$. We have done similar experiments with a two-basin ocean-only version of the present model, using analytic forms for the surface forcing (SW1), and found a reduced sensitivity: perturbations had to exceed $0.06 \mathrm{~Sv}$ to cause a reversal of the Atlantic circulation.

In the following deglaciation experiments six cases are considered: two values of the horizontal and vertical diffusivity each without wind stress and $e_{O}=e_{A}=1$ (experiments 1-4), and for $K_{V}$ and $K_{H}$ as in experiment 4 , but with wind stress we took $e_{O}=1$ (experiment 41 ) and $e_{O}=0.96$ (experiment 42 ), respectively; a summary is given in Table 3 . The six initial states are produced by spinning up from rest under restoring boundary conditions (ocean only). At steady state the atmospheric parameters are determined and the model components are coupled. For each of these six states, 30 runs were performed in the coupled mode to determine the response to different amounts $(0.02 \mathrm{~Sv}$ to $0.1 \mathrm{~Sv}$ ) of freshwater discharged at $50^{\circ} \mathrm{N}$ into the Atlantic for 1000 years. The zonality parameter $\eta_{Z}$ describing the distribution of excess precipitation was varied independently from 0 (local distribution) to 1 (zonal distribution).

The state of the global thermohaline circulation at the end of the six experiments is displayed in Fig. 12, where the white areas indicate the conveyor belt (Fig. 10a), the dark shading corresponds to the state of Fig. $10 \mathrm{~b}$ (Southern Sinking), and the coarse shading stands for the reverse conveyor belt (Fig. 10c). It is evident that the occurrence of a transition is governed primarily by the magnitude of the flux, whereas the eventual state of the system depends strongly on the zonality $\eta_{z}$. The results are consistent with the previous studies (SW1; SW2) in that for $\eta_{Z}=0$ only Southern Sinking occurs. However, the sensitivity of the present model is generally increased, and transitions can be triggered in

TABLE 3. Summary of deglaciation experiments.

\begin{tabular}{cccccc}
\hline Experiment & Figure & $\begin{array}{c}K_{H} \\
\left(\mathrm{~m}^{2} \mathrm{~s}^{-1}\right)\end{array}$ & $\begin{array}{c}K_{V} \\
\left(\mathrm{~m}^{2} \mathrm{~s}^{-1}\right)\end{array}$ & $\begin{array}{c}\text { Wind } \\
\text { stress }\end{array}$ & $\begin{array}{c}e_{O}=e_{A} \\
=1\end{array}$ \\
\hline 1 & $12 \mathrm{a}$ & $2 \times 10^{3}$ & $0.5 \times 10^{-4}$ & no & yes \\
2 & $12 \mathrm{~b}$ & $2 \times 10^{3}$ & $10^{-4}$ & no & yes \\
3 & $12 \mathrm{c}$ & $10^{3}$ & $0.5 \times 10^{-4}$ & no & yes \\
4 & $12 \mathrm{~d}$ & $10^{3}$ & $10^{-4}$ & no & yes \\
41 & $12 \mathrm{e}$ & $10^{3}$ & $10^{-4}$ & yes & yes \\
42 & $12 \mathrm{f}$ & $10^{3}$ & $10^{-4}$ & yes & no \\
\hline
\end{tabular}

cases with only $0.02 \mathrm{~Sv}$. For some parameter values we have continued integration with the flux anomaly switched off and found that most states did not undergo further transitions. (Some Southern Sinking states in parameter space close to the reversed conveyor belt eventually converged to the latter mode.) This demonstrates, depending on the choice of $\eta_{Z}$, that at least three different steady states may exist under identical boundary conditions.

Decreasing vertical diffusivity has only a minor influence on the stability of the conveyor belt but reduces the effects on the Pacific: reversals of the Pacific circulation occur less frequently. Decreasing horizontal diffusivity appears to increase stability of the global conveyor belt. If wind stress is absent (Figs. 12a-d), the reversed conveyor belt only occurs if the zonal redistribution of water by the atmosphere is large. Including wind stress, the reversed conveyor belt can be established for relatively small values of $\eta_{Z}$ increasing the sensitivity of the Pacific circulation (Fig. 12e, f). However, overall sensitivity of the global conveyor belt is decreased by wind stress (Figs. 12d,e), but the reversed conveyor belt becomes predominant already for weak zonality of precipitation. A stabilizing effect is found when we select the more realistic parameterization for the upwelling and downwelling longwave radiation at the ocean surface (Fig. 12f).

The case $\eta_{Z} \neq 0$ allows a feedback mechanism to operate that eventually triggers the reversal of the $\mathrm{Pa}$ cific thermohaline circulation necessary to establish the reversed conveyor belt. The anomalous freshwater input to the North Atlantic tends to stabilize the water column and slows down deep-water formation. Consequently, less heat is transported meridionally into the North Atlantic, causing a decrease of the SST there. According to the SST dependence of the evaporation given by (18), $E$ is reduced in the North Atlantic, which requires an equal reduction of precipitation $P$ due to the parameterization (22). A reduction of $P$ also occurs in the North Pacific, provided $\eta_{Z}>0$. This mechanism tends to diminish stability in the North Pacific and can lead to a reversal of the Pacific thermohaline circulation.

Figure 12 suggests that within the range of the tested parameters no qualitative changes of the stability of the conveyor belt result. However, quantitative details are influenced, and the atmospheric branch of the hydrological cycle (here very crudely summarized in the parameter $\eta_{Z}$ ) determines to which mode of operation the ocean will adjust for a given perturbation. It is thus important for future models of lower complexity to include also a water vapor budget in the atmosphere so as to avoid ad hoc parameterizations of these processes.

\section{Conclusions}

We have developed a latitude-depth climate model by coupling the three-basin ocean model of WS2 to a 

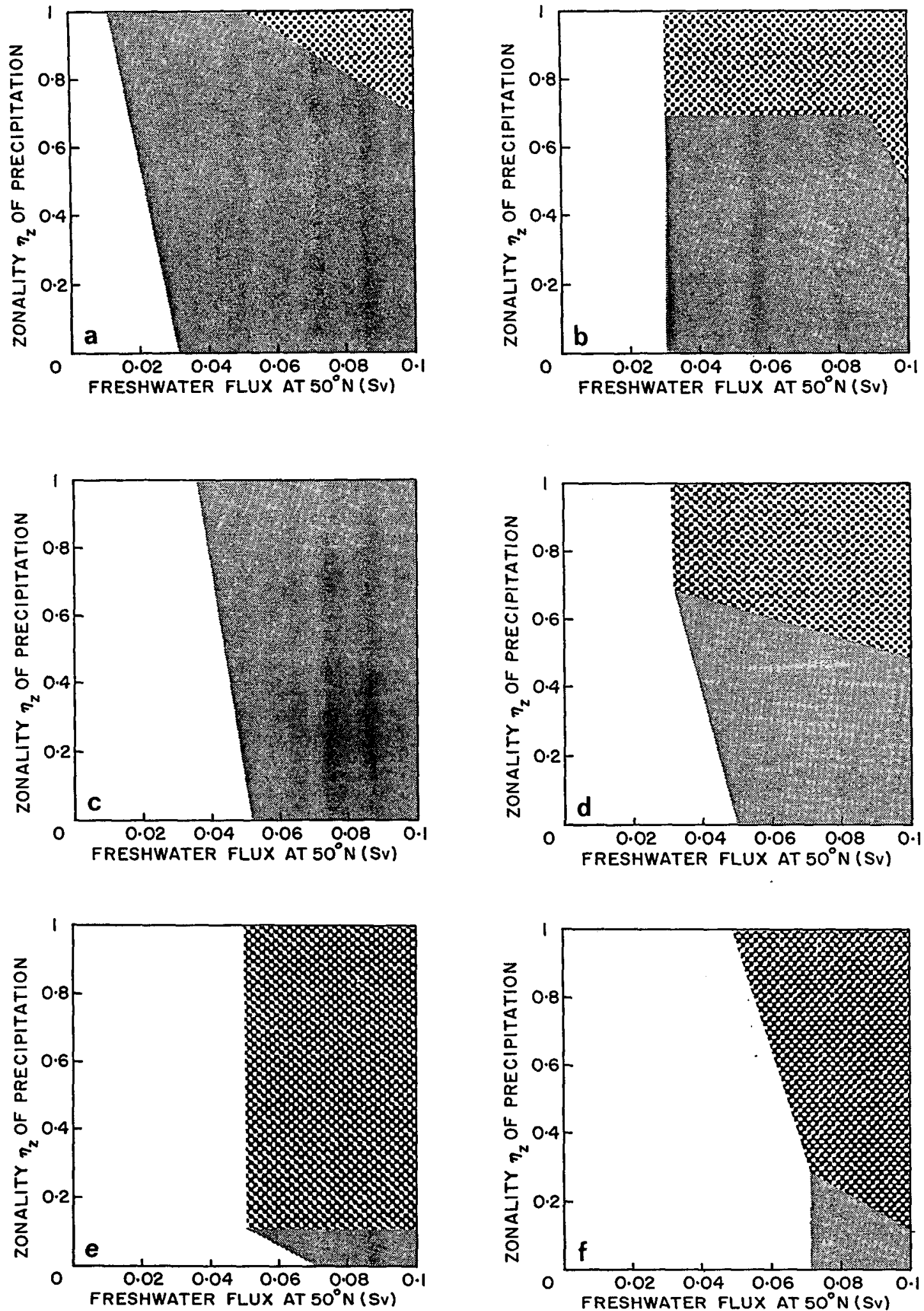

FIG. 12. State of the global thermohaline circulation after 1000 years of anomalous runoff into the North Atlantic as a function of the freshwater flux released at $50^{\circ} \mathrm{N}$ into the Atlantic and the zonality of the precipitation parameterization (22). The parameters for the six experiments in panels (a) to (f) are given in Table 3. The white area indicates the conveyor belt, the dark shading shows the state where the Atlantic thermohaline circulation is reversed (Southern Sinking), and the coarse shading marks the reversed conveyor belt. 
zonally averaged energy balance model of the atmosphere. The parameterizations accounting for air-sea exchange and atmospheric processes are kept to a minimum number and provide a self-consistent framework. Parameter values are determined objectively using the steady state of the ocean model (as spun up using observed surface data) and necessary observational data from the atmosphere. The coupled model is thus tuned to represent the present-day climate. This tuning does not influence the ocean component, and a coupled state is obtained that is in satisfactory agreement with observations in both the ocean and the atmosphere. Latitude-depth fields of temperature and salinity, depth-integrated meridional heat fluxes, and the divergence of the ocean-to-atmosphere heat and freshwater fluxes are in agreement with the data. The present-day climate is characterized by deep-water formation in the North Atlantic and the Southern Ocean and broad upwelling in the Pacific and Indian oceans.

In coupling the ocean model to an energy balance model, full-flux boundary conditions for both heat and freshwater exchanges between ocean and atmosphere are applied. In the present paper, no dynamics nor a separate water vapor budget are considered for the atmosphere. It is thus necessary to parameterize the spatial distribution of precipitation changes. We assume that the local rate of change of precipitation is due to a specified combination of local and zonal rates of change of evaporation.

In some cases a climate drift of the coupled model is evident as a gradual increase of North Pacific SSS and an eventual reversal of the Pacific thermohaline circulation. This transient behavior is in qualitative agreement with the results of a three-dimensional AOGCM (Manabe and Stouffer 1988). In the present model, we link this climate drift to intermittent convection present in the North Pacific. By time averaging the ocean-to-atmosphere fluxes before coupling, an immediate drift can be delayed for about 1000 years. It is possible to remove intermittent convection and subsequent climate drift completely if the buoyancy flux is decreased locally by a slight amount.

We find four different steady-state climates of the coupled model under identical boundary conditions. The states are again consistent with results from a threedimensional OGCM. Under present-day forcing, the global conveyor belt is always established. Freshwater anomalies discharged into the North Atlantic can trigger transitions to two other equilibria: to the Southern Sinking, where only the Atlantic thermohaline circulation is reversed, or to the reversed conveyor, for which the circulation in the Pacific and Atlantic is reversed. The fourth equilibrium, Northern Sinking (deep-water formation in both Pacific and Atlantic), is only observed as a result of climate drift. The qualitative sensitivity of the present-day climate in our model is little influenced by the presence of wind stress, different values of oceanic diffusivities, different longwave radia- tion, and precipitation parameterizations. However, the zonality of precipitation determines to which final steady state (Southern Sinking or reversed conveyor) the model will go, once a transition is initiated. This suggests that a realistic formulation of the hydrological cycle will be one of the priorities of future model development.

The ability of the model to simulate the present-day climate and its consistency with the results (both steady state and transient) from more complex, three-dimensional models are encouraging and suggest that the present model can be used as an efficient tool to systematically investigate various processes on long time scales in the climate system.

Acknowledgments. The two-year postdoctoral fellowship of the Swiss National Science Foundation awarded to TFS made this work possible and is gratefully acknowledged. This work was also supported by research grants awarded to LAM by NSERC, AES, and ONR.

\section{REFERENCES}

Baumgartner, A., and E. Reichel, 1975: The World Water Balance. Elsevier, 179 pp.

Berger, A., 1988: Milankovitch theory and climate. Rev. Geophys., 26, 624-657.

Birchfield, G. E., 1989: A coupled ocean-atmosphere climate model: Temperature versus salinity effects on the thermohaline circulation. Climate Dyn., 4, 57-71.

- H. Wang, and M. Wyant, 1990: A bimodal climate response controlled by water vapor transport in a coupled ocean-atmosphere box model. Paleoceanogr., 5, 383-395.

Boyle, E. A., and L. Keigwin, 1987: North Atlantic thermohaline circulation during the past 20,000 years linked to high-latitude surface temperature. Nature, 330, 35-40.

Broecker, W. S., and G. H. Denton, 1989: The role of ocean-atmosphere reorganizations in glacial cycles. Geochim. Cosmochim. Acta, 53, 2465-2501.

- D. M. Peteet, and D. Rind, 1985: Does the ocean-atmosphere system have more than one stable mode of operation? Nature, 315, 21-26.

Bryan, F., 1986: High-latitude salinity effects and interhemispheric thermohaline circulations. Nature, 323, 301-304.

, 1987: Parameter sensitivity of primitive equation ocean general circulation models. J. Phys. Oceanogr., 17, 970-985.

- and W. R. Holland, 1989: A high resolution simulation of the wind- and thermohaline-driven circulation in the North Atlantic Ocean. 'Aha Huliko'a, Parameterization of Small-Scale Processes, P. Müller and D. Henderson, Eds., Hawaii, Inst. of Geophys., 99-115.

Bryan, K., and L. J. Lewis, 1979: A water mass model of the World Ocean. J. Geophys. Res., 84, 2503-2517.

Bryden, H. L., and M. M. Hall, 1980: Heat transport by currents across $25^{\circ} \mathrm{N}$ latitude in the Atlantic Ocean. Science, 207, 884885 .

Budyko, M. I., 1969: The effect of solar radiation variations on the climate of the earth. Tellus, 21, 611-619.

Carissimo, B. C., A. H. Oort, and T. H. Vonder Haar, 1985: Estimating the meridional energy transports in the atmosphere and ocean. J. Phys. Oceanogr., 15, 82-91.

Denton, G. H., and T. J. Hughes, 1981: The Last Great Ice Sheets. Wiley, 484 pp.

Duplessy, J. C., N. J. Shackleton, R. G. Fairbanks, L. Labeyrie, D. Oppo, and N. Kallel, 1989: Deepwater source variations during the last climatic cycle and their impact on the global deepwater circulation. Paleoceanogr., 3, 343-360. 
Fiadeiro, M. E., and G. Veronis, 1977: On weighted-mean schemes for the finite-difference approximation to the advection-diffusion equation. Tellus, 29, 512-522.

Fichefet, T., C. Tricot, A. Berger, H. Gallée, and I. Marsiat, 1989: Climate studies with a coupled atmosphere-upper-ocean-icesheet model. Phil. Trans. R. Soc. London, A329, 249-261.

$\mathrm{Fu}, \mathrm{L}$. L., 1986: Mass, heat and freshwater fluxes in the south Indian Ocean. J. Phys. Oceanogr., 16, 1683-1693.

'Gill, A. E., 1982: Atmosphere-Ocean Dynamics, Int. Geophys. Ser., Vol. 30. Academic Press, 662 pp.

Gordon, A. L., 1986: Interocean exchange of thermocline water. $J$. Geophys. Res., 91, 5037-5046.

Hall, M. M., and H. L. Bryden, 1982: Direct estimates and mechanisms of ocean heat transport. Deep-Sea Res., 29, 339-359.

Han, Y.-J., and S.-W. Lee, 1983: An analysis of monthly mean wind stress over the global ocean. Mon. Wea. Rev., 111, 1554-1566.

Haney, R. L., 1971: Surface thermal boundary condition for ocean general circulation models. J. Phys. Oceanogr., 1, 241-248.

Hastenrath, S., 1982: On meridional heat transports in the World Ocean. J. Phys. Oceanogr., 12, 922-927.

Harvey, L. D. D., 1988: A semianalytic energy balance climate model with explicit sea ice and snow physics. J. Climate, 1, 10651085.

—, and S. H. Schneider, 1985a: Transient climate response to external forcing on $10^{\circ}-10^{4}$ year time scales. Part 1: Experiments with globally averaged, coupled, atmosphere and ocean energy balance models. J. Geophys. Res., 90, 2191-2205.

- and $-1985 \mathrm{~b}$ : Transient climate response to external forcing on $10^{\circ}-10^{4}$ year time scales. Part 2: Sensitivity experiments with a seasonal, hemispherically averaged, coupled, atmosphere, land, and ocean energy balance model. J. Geophys. Res., 90, 22072222.

Held, I. M., and M. J. Suarez, 1978: A two-level primitive equation atmospheric model designed for climatic sensitivity experiments. J. Atmos. Sci. 35, 206-229.

Hoffert, M. I., A. J. Callegari, and C.-T. Hsieh, 1980: The role of deep sea heat storage in the secular response to climatic forcing. J. Geophys. Res., 85, 6667-6679.

Holton, J. R., 1979: An Introduction to Dynamical Meteorology, Int. Geophys. Ser., Vol. 23. Academic Press, 391 pp.

Hsiung, J., 1985: Estimates of global oceanic meridional heat transport. J. Phys. Oceanogr., 15, 1405-1413.

Isemer, H.-J., and L. Hasse, 1987: The Bunker Climate Atlas of the North Atlantic, Vol. 2: Air-Sea Interactions. Springer, $252 \mathrm{pp}$.

Levitus, S., 1982: Climatological atlas of the World Ocean. NOAA Prof. Paper, No. 13, 177 pp.

Lorenz, E. N., 1979: Forced and free variations of weather and climate. J. Atmos. Sci., 36, 1367-1376.

MacCracken, M. C., and S. J. Ghan, 1988: Design and use of zonallyaveraged climate models. Physically-Based Modelling and Simulation of Climate and Climatic Change, M. E. Schlesinger, Ed., Kluwer, 755-809.

Maier-Reimer, E., and U. Mikolajewicz, 1989: Experiments with an OGCM on the cause of the Younger Dryas. Oceanography, A. Ayala-Castañares, W. Wooster, and A. Yáñez-Arancibia, Eds., UNAM Press, 87-100.

Manabe, S., and R. J. Stouffer, 1988: Two stable equilibria of a coupled ocean-atmosphere model. J. Climate, 1, 841-866.

Marotzke, J., 1989: Instabilities and steady states of the thermohaline circulation. Ocean Circulation Models: Combining Data and Dynamics, D. L. T. Anderson and J. Willebrand, Eds., Kluwer, 501-511.

- 1990: Instabilities and multiple equilibria of the thermohaline circulation. Ber. Inst. Meeresk. Kiel, 194, 126 pp.

— , and J. Willebrand, 1991: Multiple equilibria of the global thermohaline circulation. J. Phys. Oceanogr., 21, 1372-1385.
, P. Welander, and J. Willebrand, 1988: Instability and multiple equilibria in a meridional-plane model of the thermohaline circulation. Tellus, 40A, 162-172.

Milankovitch, M., 1941: Kanon der Erdbestrahlung und seine Anwendung auf das Eiszeitproblem. Roy. Serb. Acad. Special Publication, No. 133, 1-633. Belgrade.

Oort, A. H., 1983: Global atmospheric circulation statistics, 19581973. NOAA Prof. Paper, No. 14, 180 pp.

Peixóto, J. P., and A. H. Oort, 1984: Physics of climate. Rev. Mod. Phys., 56, 365-429.

Rago, T. A., and H. T. Rossby, 1987: Heat transport into the North Atlantic Ocean north of $32^{\circ} \mathrm{N}$ latitude. J. Phys. Oceanogr., 17, 854-871.

Roemmich, D., 1980: Estimates of meridional heat flux in the North Atlantic by inverse methods. J. Phys. Oceanogr., 10, 1972-1983.

Rooth, C., 1982: Hydrology and ocean circulation. Prog. Oceanogr. 11, 131-149.

Sellers, W. D., 1969: A global climatic model based on the energy balance of the earth-atmosphere system. J. Appl. Meteor., 8 , $392-400$.

Stephens, G. L., G. G. Campbell, and T. H. Vonder Haar, 1981: Earth radiation budgets. J. Geophys, Res., 86, 9739-9760.

Stocker, T. F., and D. G. Wright, 1991 a: A zonally averaged ocean model for the thermohaline circulation. Part II: Interocean circulation in the Pacific-Atlantic basin system. J. Phys. Oceanogr. 21, 1725-1739.

$\longrightarrow$, and $-1991 \mathrm{~b}$ : Rapid transitions of the ocean's deep circulation induced by changes in the surface water fluxes. Nature 351, 729-732.

- - , and L. A. Mysak, 1991: Experiments with a coupled, zonally averaged atmosphere-ocean model: Variability of the thermohaline circulation. Int. Conf. on the Role of the Polar Regions in Global Change, University of Alaska, Fairbanks, 291295

Stommel, H., 1961: Thermohaline convection with two stable regimes of flow. Tellus, 13, 224-230.

Talley, L. D., 1984: Meridional heat transport in the Pacific Ocean. J. Phys. Oceanogr., 14, 231-241.

Vallis, G. K., 1982: A statistical-dynamical climate model with a simple hydrology cycle. Tellus, 34, 211-227.

Warren, B. A., 1981: Deep circulation of the World Ocean. Evolution of Physical Oceanography, Scientific Surveys in Honor of Henry Stommel, B. A. Warren and C. Wunsch, Eds., MIT Press, 641.

Weaver, A. J., and E. S. Sarachik, 199la: Evidence for decadal variability in an ocean general circulation model: An advective mechanism. Atmos.-Ocean, 29, 197-231.

- and $-199 \mathrm{lb}$ : The role of mixed boundary conditions in numerical models of the ocean's climate. J. Phys. Oceanogr. 21, 1470-1493.

Welander, P., 1986: Thermohaline effects in the ocean circulation and related simple models. Large-Scale Transport Processes in Oceans and Atmosphere, J. Willebrand and D. L. T. Anderson, Eds., Reidel, 163-200.

Wright, D. G., 1992: Finite difference approximations to the advection-diffusion equation. Tellus (in press).

- , and T. F. Stocker, 1991: A zonally averaged ocean model for the thermohaline circulation. Part I: Model development and flow dynamics. J. Phys. Oceanogr., 21, 1713-1724.

$\longrightarrow$, and - 1992: Sensitivities of a zonally-averaged global ocean circulation model. J. Geophys. Res., in press.

Wunsch, C., 1984: An eclectic Atlantic Ocean circulation model. Part I: The meridional flux of heat. J. Phys. Oceanogr., 14, 17121733.

Zaucker, F., and W. S. Broecker, 1992: Atmospheric water vapor transport from a general circulation model. J. Geophys. Res. 97, 2765-2773. 